A Critical Review of Cognitive Load Lie Detection and Suggestions for

\title{
Future Research
}

(Word count: 9,230)

This manuscript was a working draft that I have split into two manuscriptsNEVER quote directly from this text. The split was necessary to free space and allow me to delve into the issues under discussion.

- One half of the split is a metascientific empirical investigation into a set of published articles: https://psyarxiv.com/5d6tj

- The other half focuses purely on discussing arguments exponents:

https://psyarxiv.com/yd45e

David A. Neequaye

Department of Psychology

University of Gothenburg

\section{Author note}

When writing this article, I have learned the most from conversations with and comments from Karl Ask, Irena Boskovic, Pär Anders Granhag, and Erik Mac Giolla (listed alphabetically by surname). Many thanks to Jasmine Afram for assisting me with data extraction. I am fully and solely responsible for any errors in this article.

Correspondence to: David A. Neequaye, Department of Psychology, University of Gothenburg. Box 500, 40530 Gothenburg, Sweden; Email: david.neequaye@psy.gu.se 
Data Availability Statement: All data supporting the findings in this research are publicly available publications, and the present manuscript contains the pertinent aspects. 


\begin{abstract}
This article critically examines the idea that cognitive load interventions can expose lies. I discuss the theoretical ambiguities of seven popular justifications of cognitive load lie detection. For example, liars must suppress the truth while lying: this handicap makes lying challenging such that one can exploit the challenge by inducing more cognitive load to expose lies. Each of those seven justifications can hardly be falsified. Moreover, the theoretical fitness of each justification is variable and unclear. A thematic review indicated that researchers substantially rely on the customary seven justifications to support cognitive load lie detection despite the shortcomings. I propose research questions whose answers could help ascertain the theoretical fitness of the seven justifications and the cognitive load lie detection premise. Going forward, stakeholders must focus on falsifying the basic premise of cognitive load lie detection: such efforts will determine the future of the idea.
\end{abstract}

Keywords: cognitive load; investigative interviewing; lie detection; lying; truthtelling 


\section{A Critical Review of Cognitive Load Lie Detection and Suggestions for}

\section{Future Research}

The prevailing view on tackling lie detection is that focusing on human cognition is likely the most productive path. Psychology researchers espouse various approaches aimed at generating different mental processes and verbal strategies between liars and truth-tellers (see, e.g., Vrij, 2019 for an overview). Within the current school of thought, cognition-based lie detection, a dominant perspective is that investigators can use cognitive load interventions to expose lies. That idea continues to gain traction in research and forensic contexts (e.g., Schafer, 2020; Vrij, Meissner, et al., 2017). This review critically examines cognitive load lie detection and raises issues for future research. I will focus on seven popular justifications of cognitive load lie detection. A prominent example is that liars must suppress the truth while lying: this handicap makes lying challenging such that inducing more cognitive load can expose lies (e.g., Vrij, 2015). Before delving into those justifications, the discussion will examine the theoretical foundation of cognitive load lie detection and the importance of justifying it.

Zuckerman et al. (1981) asserted that, generally, lying demands more cognitive resources than truth-telling. "Creating the details of a [plausible] lie is a more difficult task than telling the truth (p. 10)." In this article, lying means a sender making a believed-false statement to another person, the receiver: (a) to make the receiver believe that statement as true; or (b) to convince the receiver that the sender believes 
that statement as true; or (c) the sender intends $a$ and $b$ (Mahon, 2008). Psychology researchers, especially within the Legal/Forensic domain, sometimes draw on Zuckerman et al.'s (1981) proposition when developing techniques or methods to detect lying ${ }^{1}$. The extant literature, called "the cognitive [load] approach to lie detection", recommends several techniques (see, e.g., Vrij, 2015; Vrij, Fisher, et al., 2017). The proponents have grouped those techniques into three broad categories. Next follows a summary based on Vrij (2015) and Vrij, Fisher, et al. (2017), who discuss the taxonomy in detail.

- Imposing cognitive load. This category refers to interventions designed to make the interview setting more mentally challenging. For example, the receiver, a person posing questions, could ask the sender to provide their response in reverse temporal order (e.g., Vrij et al., 2012).

- Encouraging interviewees to provide more information. The name of this category is also its definition. Specific techniques under this classification include requesting drawings in addition to spoken or written messages (e.g., Leins et al., 2011).

- Unexpected questions. This designation refers to methods of questioning that pose inquiries interviewees do not anticipate. Examples of such unanticipated

\footnotetext{
${ }^{1}$ I refrain from using the word deceive and its variants (e.g., deception) unless to quote a source directly. Analysts (e.g., Mahon, 2008) argue that to deceive possibly implies a sender has achieved the goal of the lie. However, lying can be unsuccessful.
} 
questions include asking about spatial and temporal information (e.g., Vrij et al., 2009).

Exponents argue that cognitive load techniques compound the liar's presumed uphill battle by exacerbating the mental demand of producing a plausible lie. Consider the following premise that forms the bedrock of cognitive load lie detection.

"If lying requires more cognitive resources than truth-telling, liars will have fewer cognitive resources leftover [emphasis added]. If cognitive demand is further raised [emphasis added], which could be achieved by making additional requests [emphasis added], liars may not be as good as truth tellers in coping with these additional requests" (Vrij \& Granhag, 2012, p. 113).

The premise invokes a counterfactual: that the mental strain cognitive load enhances is one the would-be liar will inevitably experience if they lie. There are studies wherein, after interviews, liars have reported experiencing more cognitive load than truth-tellers did (e.g., Granhag \& Strömwall, 2002; Strömwall et al., 2006). At a minimum, liars must manufacture some details and, all things being equal, truth-tellers relay known information. Ostensibly, that difference presents a level of difficulty one can exploit (e.g., Vrij, 2015). Thus, cognitive load lie detection assumes questioning methods can introduce non-trivial challenges for would-be liars, and those non-trivial difficulties can expose lying. Recent evidence suggests one cannot take that proposition for granted ${ }^{2}$.

\footnotetext{
${ }^{2}$ In the appendix, I explore an alternative interpretation of the cognitive load lie detection premise.
} 
A meta-analysis by Vrij, Fisher, et al. (2017) demonstrated that cognitive load techniques, compared to control conditions, improved lie detection $(d=\sim .40$; Vrij et al., 2018) But see Levine et al. (2018) for a critical reanalysis of Vrij, Fisher, et al. (2017). Additionally, two subsequent meta-analyses (Mac Giolla \& Luke, 2021; Verschuere et al., 2018) give cause for further scrutinizing the basis of cognitive load lie detection. Researchers typically employ reaction time as a lie detection cue, and they propose that people deliver lies more slowly than truths (e.g., Walczyk et al., 2003). Researchers assume that slower reaction times indicate one was contending with a heavier cognitive load. Verschuere et al. (2018) investigated whether imposing cognitive load during questioning increased the presumed difference between how quickly people deliver lies versus truths. The results revealed that people told the truth faster than lies. Nonetheless, the imposing of cognitive load did not increase that difference. On the contrary, cognitive load slowed down the expected speed of truthtelling, obscuring the ability to detect lies from truths via reaction times (see also, Frank et al., 2019; Jordan, 2016).

Mac Giolla and Luke (2021) examined whether methods of questioning based on the cognitive load lie detection premise improve observers' ability to detect lies. The cognitive load approach improved lie detection by $7 \%$ compared to control conditions; those gains rose to $27 \%$ when observers knew the relevant cues to focus on. The authors note that those gains are promising and admonish us to be optimistic about the future of cognitive load lie detection. But researchers would be prudent to remain skeptical 
considering the significant limitations the authors raise about the improvement cognitive load lie detection brings. "This promising result is qualified by indications of publication bias, considerable heterogeneity between studies, and a lack of research on important practical issues, such as the influence of counter-measures (Mac Giolla \& Luke, 2021)." Moreover, the authors note that few studies in their meta-analysis included informed observers; those studies typically employed research designs wherein training effects may have confounded the accuracy rates. Other reviews have also revealed that the strengths of various lie detection cues seem to decline the more researchers study them (Luke, 2019).

The meta-analyses (viz, Mac Giolla \& Luke, 2021; Verschuere et al., 2018) highlight the need to peruse the foundation of cognitive load lie detection (see also, Frank et al., 2019; Jordan, 2016). That is, the idea that inducing cognitive load can introduce non-trivial challenges for would-be liars, and those non-trivial difficulties can expose lies. Exponents must elucidate the properties of lying versus truth-telling that make lying susceptible to become significantly more taxing when a receiver poses an ostensibly difficult question. In doing so, advocates can justify their central claim that imposing cognitive load can cause consequential differences between lying and truthtelling.

Taking the cognitive load approach's rationale for granted conceals (a) the need for justification and (b) scrutiny of said rationale. These two blind spots allow the basis of cognitive load lie detection to go unquestioned even though the proposal is 
due for a critical analysis. For other critical reviews see Blandón-Gitlin et al. (2014, on mechanisms) Walczyk et al. (2013, on mechanisms and countermeasures); and Sporer (2016, on an alternative theory about cognitive load and lying). The present review focuses on justifications.

\section{The Justifications of Cognitive Load Lie Detection}

Cognitive load lie detection research primarily aims to improve investigative interviewing wherein interviewees, namely, liars and truth-tellers, share a common goal of appearing plausible to their interviewer. In forensic settings, interviewees face material risks if they appear dubious; for example, they may become prime suspects or be convicted. In some cases, a truth-teller whose message does not seem credible may fail to effectively relay critical information an investigation needs. That error may bring miscarriages of justice.

Explanations of why lying can become significantly laborious should account for the plight of liars and truth-tellers; call such an explanation justification- $i$. Justification- $i$ is likely problematic if it overly places the challenge of one group in focus. Assume justification- $i$ places more attention on the challenges and the concomitant mental strain faced by liars. In that case, justification- $i$ might erroneously permit the prediction that inducing cognitive load aggravates liars' challenge more than truth-tellers'. However, the reality might be that when the scenario justification$i$ presents is scrutinized, truth-tellers also face marked predicaments that cognitive load can compound (see, e.g., Frank et al., 2019; Verschuere et al., 2018). As such, 
justification- $i$ does not necessarily warrant the notion that imposing cognitive load will heighten problems for liars to a larger extent; truth-tellers might suffer similar predicaments. Then, the underspecified justification- $i$ creates a blind spot, obscuring insight into how liars and truth-tellers behave when facing taxing questions. In the worst-case scenario, justification- $i$ may lead an interviewer to misclassify a truth-teller as a liar if the truth-teller cannot perform as fluently as the interviewer expects.

Apart from accounting for the behaviors of truth-tellers, justification- $i$ must be logically coherent. Justifications that explain why lying is liable to become markedly straining are the necessary auxiliaries upon which cognitive load lie detection rests. Analysts note that if such auxiliaries suffer coherence limitations or lack empirical support, the hypotheses tests resting on those unsubstantiated auxiliaries have limited validity (e.g., Meehl, 1990; Scheel et al., 2021). Conversely, sound auxiliaries allow valid hypothesis testing.

To my knowledge, the literature contains a recurring list of seven reasons justifying why lying can become considerably more challenging than truth-tellingsuch that imposing cognitive load will expose lies (see, e.g., Vrij et al., 2011; Vrij, 2015, p. 206 - 208; see also Leal et al., 2008; Leal \& Vrij, 2008; Vrij, 2014; Vrij, 2008, p. 39 - 41; Vrij et al., 2010; Vrij \& Ganis, 2014, p. 320 - 321).

- $\quad$ Liars must monitor their lies to remain plausible and consistent.

- $\quad$ Liars are less likely to take their credibility for granted than truth-tellers would.

- $\quad$ Liars monitor receivers' reactions to assess whether a lie is being believed. 
- Liars may be engrossed in reminding themselves to play the role of a truthteller.

- $\quad$ Lying requires a mental justification truth-telling does not.

- $\quad$ Liars have to suppress the truth while lying.

- The mental activation of a lie is deliberate, but the truth often comes to mind automatically.

I will examine each of the outlined justifications by exploring the predicaments they present to both liars and truth-tellers. I will also explore the limitations in the coherence of any justification when necessary. The upcoming critical analysis has two goals: (a) to explore whether the extant justifications sufficiently license cognitive load lie detection such that one can falsify the notion; and (b) to identify issues for future research that can better place cognitive load lie detection in a position to allow falsification. Table 1 provides an overview of the research gaps the research field must attend to if the field wants to arrive at a suitable place: one where the cognitive load lie detection premise can be falsified.

\section{Plausibility and Consistency}

Vrij (2015) notes that conjuring a lie is arduous and explains why in three parts: next follows a summary. First, apart from manufacturing the details, the liar must monitor the lie to ensure it is plausible. The lie must align with what the receiver knows or might discover. Second, liars must remember their previous messages and the corresponding receivers. In doing so, the liar can appear consistent when repeating 
the previous message. Third, "liars should also avoid making slips of the tongue and should refrain from providing investigators with new leads (Vrij, 2015, p. 206)".

Let us now examine the justification just described, beginning with the claims about plausibility and consistency. Preparing a lie in advance likely alleviates the burden of manufacturing details on the spot. Hence, any difficulty with conjuring lies likely happens when the liar needs to invent a message instantly; say the question is unexpected. Asking unanticipated questions forms one of the main strands of cognitive load lie detection. All things being equal, a truth-teller knows the information the interviewer is requesting even if the question is unexpected. However, why liars versus truth-tellers are more inclined to suffer the three-part predicament remains unclear. Note that the interviewer does not know the would-be liar or truth-teller beforehand. If the interviewer knew who would lie, the interview would be unnecessary because the interviewer would also likely know the information in advance.

On average, we can expect that neurotypical people in forensic investigative interviews will want their message to appear plausible and consistent, given the risks of seeming dubious. A truth-teller is also likely to monitor their response to an unexpected question; arguably, neurotypical truth-tellers would want their answer to align with what the receiver knows or might discover. In doing so, truth-tellers will aim to be consistent with any previous messages; or any aspects of the issue under discussion. Truth-tellers likely suffer predicaments with respect to providing plausible and consistent responses to unexpected questions. The nature of those challenges may 
differ from what liars face; nonetheless, important challenges arise for both liars and truth-tellers.

One cannot assume that because truth-tellers versus liars ostensibly have the answers to unanticipated questions in their memory stores, truth-tellers can respond with more ease. Even if a truth-teller claims they remember the event to be discussed, note that they now have unexpected questions to contend with. A hurdle they have not yet considered; otherwise, the questions would not be unanticipated. We cannot take it for granted that truth-tellers will have a less demanding task to surmount. Researchers must first outline the cognitive mechanisms underlying how would-be liars and truth-tellers answer unanticipated questions - to appear plausible and consistent.

The highlighted gap in the literature also calls for analysts to nominate a definition and specify a falsifiable theory that systematically delineates question-types interviewees would generally not anticipate and why. Such research will reduce ambiguity about what qualifies as an unexpected question and, by extension, improve measurement practices in this area of study. Without such specification to offer an objective yardstick, one could call any manipulation an unanticipated question. This loophole invites questionable research practices and argumentation. Suppose a manipulation fails to achieve the hypothesized effect of exposing lies from truths. Then one could blame the manipulation, not the cognitive load lie detection premise. Addressing the highlighted gaps in the literature will help clarify the potential effects of unexpected questions on lying and truth-telling. 
The final aspect of the three-part challenge liars versus truth-tellers are presumably more inclined to tackle concerns avoiding slips of the tongue and providing new leads (Vrij, 2015). Assume "slips of the tongue" and "new leads" respectively denote certain things liars must conceal. Suppose the thing liars must hide is the fact that their message is a lie; say, a liar must conceal that they are making a believedfalse statement. In that case, the justification hardly specifies why lying is prone to becoming more difficult than truth-telling, much less that one can capitalize on the presumed challenge to expose lies. Alternatively, we can assume the slippage liars must avoid is some event, which, if exposed, can derail the communication or success of the lie. Then, a theory is needed to systematically predict how the nature of such an event can make lying versus truth-telling laborious. The event a liar may want to conceal can vary on several relevant dimensions, for example, the complexity and the time the event occurred relative to the current interview (e.g., Sporer, 2016). The literature needs to better specify the important ways in which concealing information is different from lying. Concealing information is essentially an aspect of lying (McCornack, 1992). Then exponents must also specify how those differences make lying taxing such that one can exploit that burden to reveal lies.

\section{Concern about Credibility}

Another justification claims that liars versus truth-tellers will be less likely to take their credibility for granted (Vrij, 2015); exponents offer two reasons to support that claim. The first reason indicates that the stakes are sometimes greater for liars 
than truth-tellers. Such high-stakes mean the negative repercussions of a lie being exposed and the advantages of the lie succeeding (Vrij, 2015). Second, the proposal notes that truth-tellers usually presume their innocence will be apparent because of certain cognitive biases. Truth-tellers assume their truth will "shine through" (Vrij et al., 2010). According to Vrij (2015), truth-tellers suppose that people get what they deserve (viz., the just-world hypothesis, Lerner, 1998); truth-tellers also overestimate how perceptible their mental states are to others (viz., the illusion of transparency, Gilovich et al., 1998). Conversely, liars will be prone to monitoring and controlling their demeanor to appear honest. This burden makes the cognitive strain of lying susceptible to become compounded under cognitive load.

The definition of high-stakes is framed in a manner that obscures scrutiny. High-stakes seem to apply to liars only; namely, "[the] negative consequence of getting caught and [the] positive consequence of getting away with the lie [emphasis added] (Vrij, 2008, 2015)." Because that definition of high-stakes necessarily excludes truthtellers, the definition conceals the need to contemplate the plight of truth-tellers in the same situation. Let us reformulate that definition of high-stakes to allow a comparison between liars and truth-tellers but retain the sentiment in the original definition. Take the phrase high-stakes to mean a negative consequence of not being believed and a positive consequence of being believed.

Given the risks of appearing dubious in an investigative interview, one should expect neurotypical truth-tellers to be concerned about their credibility just as liars 
would. Remember that being subjected to an interview signals that, at a minimum, the interviewer is trying to find out some true information. Arguably, neurotypical adults will expect that their messages will not necessarily be taken for granted by their interviewer. Suppose there are significant gains to achieve if one is believed and grave dangers if the interviewer is not convinced. In that case, the hypothesis to expect is that both liars and truth-tellers will be similarly concerned about their credibility. For example, neurotypical suspects being interviewed about their possible involvement in a murder should be concerned about their credibility, irrespective of their culpability. If they appear dubious, they might become prime suspects and may later serve a prison sentence. Thus, whatever cognitive demand high-stakes induces, that strain should tax both liars and truth-tellers, not just liars.

Let us consider whether the just-world hypothesis and the illusion of transparency license the claim that truth-tellers typically take their credibility for granted more than liars do. Assume that those cognitive biases, indeed, manifest in the high-stakes scenarios defined previously. In this view, truth-tellers will take their believability for granted, not minding that they might fail to convince their interviewer and the consequences that possibility can invite. Suppose we grant that those cognitive biases are so formidable to lead truth-tellers to assume the veracity of their message will be evident without question. Then, we should expect would-be liars to perfectly refrain from lying in high-stakes scenarios; their mental states will presumably be perceptible, and in a just-world, they would definitely suffer the deserved consequences 
for lying. Nonetheless, people do lie when there are potentially grave consequences for doing so. One cannot assume the cognitive biases absolve truth-tellers from being concerned about their credibility. Granting that assumption would suggest that those cognitive biases perfectly stifle lying, which is not the case.

A possible explanation to the theoretical issues I have raised is this: liars are inclined to take a risk. At the same time, truth-tellers hope for the best outcome. That explanation addresses why people lie in high-stakes scenarios. Nevertheless, the explanation does not elucidate why one should expect liars to be more concerned about their credibility than truth-tellers will. One can hope for the best outcome and still be concerned about their credibility just as the person taking a risk. A truth-teller can relay their truth, expecting to be convincing but remain concerned about their credibility. The pressing questions remain unanswered. First, exponents must clarify the definition of high-stakes. Then analysts can answer the following essential questions. Do truth-tellers perceive high-stakes differently than liars do? Does risktaking versus hoping for the best outcome affect concern about credibility in different ways? Crucially, does that difference yoke liars with a challenge one can capitalize on to expose lies?

\section{Monitoring Success}

The present justification of cognitive load lie detection builds on the concernabout-credibility claim described previously. The current contention extends that claim and supposes that liars may surveil their targets to check if the lie is succeeding; 
such monitoring consumes cognitive resources (e.g., Vrij, 2008, 2014, 2015). Two references (viz., Buller \& Burgoon, 1996; Schweitzer et al., 2002) often accompany the notion that liars monitor receivers' reactions. Broadly speaking, the Interpersonal Deception Theory (IDT) posits that communication is dynamic; interlocutors, in this case, liars, adapt their communication based on receivers' feedback to be successful (Buller \& Burgoon, 1996). Schweitzer et al. (2002) describe a particular instance they call a monitoring-dependent lie. They note that such lies usually require the liar to monitor the receiver; for example, when one equivocates on a bluff depending on the receiver's initial reaction. Schweitzer et al. (2002) found that people specifically capitalize on visual access to execute monitoring-dependent lies effectively.

The IDT (Buller \& Burgoon, 1996) and the study by Schweitzer et al. (2002) suggest that liars might monitor receivers' reactions to track the success of a lie. However, those examinations pertain to lying, not a comparison between lying and truth-telling. Why - in an investigative interview - liars versus truth-tellers would be more inclined to monitoring remains unclear. The current justification makes no predictions about truth-tellers; this lack conceals the need to consider how truth-tellers might behave. Interviews implicitly or explicitly call on interviewees to be convincing. We can assume a truth-teller will want to be believed even if they expect the truth to shine through. Thus, it is feasible to expect a truth-teller also to check the reactions of their interviewer to assess whether the interviewer believes the truth being reported. For example, a truth-teller might clarify aspects of their message if the interviewer 
expresses disbelief in any way. A research gap worth exploring here is whether liars and truth-tellers necessarily monitor receivers in different ways and whether those differences the moderate the cognitive load lie detection premise.

\section{Preoccupation with Role-play}

A factor posited to contribute to liars' cognitive load is that liars might get absorbed in reminding themselves to act like truth-tellers. Drawing on DePaulo et al. (2003), the proponents posit that such role-play requires extra cognitive effort (e.g., Vrij, 2008, 2014, 2015).

Based on the idea of self-presentation (e.g., Schlenker \& Pontari, 2000), DePaulo et al. (2003) note that lying and truth-telling involve the tendency to portray certain behaviors to receivers: personal qualities aimed at making the receiver believe the sender is sincere. Because the claims liars make are false, DePaulo et al. (2003) argue that liars' self-presentation should be more deliberate than truth-tellers. Liars try to behave like they imagine truth-tellers would. Consequently, the authors predicted that liars' performance would seem less forthcoming, less convincing, less pleasant, and tenser insofar as liars act more deliberately than truth-tellers.

A recent meta-analysis has demonstrated that the cues of lying just mentioned are tenuous (Luke, 2019). Moreover, DePaulo et al. (2003) explicitly reject the argument that lies, by definition, are more difficult to construct than truths. The authors further note that the self-regulation that attends deliberate behavior does not always hamper performance; the self-regulatory demands on liars do not necessarily 
surpass what truth-tellers experience. Such qualifications raise issues with the justification this section focuses on: the idea that because liars deliberately act like truth-tellers, liars will be preoccupied with role-playing and, in doing so, spend more mental resources. As DePaulo et al. (2003) discuss, truth-tellers might well be preoccupied too. Given the risks failure might attract, neurotypical truth-tellers will want to portray personal qualities and deliver their messages in ways they believe will strengthen their credibility.

Three research gaps become evident. (a) Future theories must specify how selfregulation manifests in an investigative interview: do liars and truth tellers inevitably self-regulate in different ways? See Vohs and Baumeister (2016) for an in-depth discussion of self-regulation. (b) Does such self-regulation elicit different levels of cognitive load that one can exploit to expose lies? (c) Advocates must additionally elucidate how that difference, if one exists, hampers the construction of lies versus truths.

\section{The Basis for Lying}

An extant rationale of cognitive load lie detection is the assertion that lying requires a justification, but truth-telling does not (e.g., Vrij, 2014, 2015). The proponents argue that people usually lie because material and psychological reasons motivate them to do so. Ostensibly, considering those reasons drains mental resources because, after each question, a liar must decide whether lying is a worthwhile response (Vrij, 2014, p. 186). 
When theorists invoke the present justification, they consistently cite Levine et al. (2010) as support; see, for example, Vrij (2014, p. 186, 2015, p. 207) and Vrij and Ganis (2014, p. 321). Levine et al. (2010) explicitly claim to empirically examine Bok's (1999) exposition of the maxim that people typically prefer to tell the truth if they have no reason to lie. Thus, the present premise of cognitive load lie detection stems from Bok (1999). Bok notes that humans generally consider lying morally reprehensible; lying erodes trust in human relations. That indictment creates an initial imbalance wherein lying carries a negative moral valence. Sometimes, however, lying is a person's last resort, and such instances reasonably invite us to consider whether lying is morally justified (Bok 1999). For example, a person lying due to an unexamined good intention: telling a friend their unpalatable meal is delightful to prevent hurt feelings. In this view, a discovered lie requires an explanation, but a discovered truth does not (Bok 1999, p. 32). Humans behave in ways suggesting they want to avoid the potential disrepute lying brings (e.g., Levine et al., 2010).

Now let us reconsider the claim that lying saps mental resources because one has to decide whether lying is worthwhile (Vrij, 2014, p. 186). Suppose one decides in advance to lie and prepares those lies as the extant literature indicates liars in investigative interviews do (e.g., Hartwig et al., 2007). Then, such would-be liars have already decided that lying is worthwhile and will likely not be contending with moral justifications during their interview. What about unanticipated questions, which become relevant here? Is the moral justification of lying a significant item would-be 
liars contemplate after receiving an unexpected question? If so, does that contemplation necessarily make lying straining such that one can exploit the strain?the present rationale does not specify.

A relevant competing hypothesis is evident here: liars are likely to be most concerned with the material risks an investigative interview presents, for example, becoming a prime suspect if the interviewer discovers the lie. In this view, the moral legitimacy of lying will likely be trivial to liars. Possibly appearing morally reprehensible is arguably not a material risk, at least not an important one. Liars will be concerned with constructing plausible lies that will evade suspicion. If a liar were to summon cognitive resources, the primary consumer would likely be their attempt to navigate any material risks. Mentally justifying the moral legitimacy of the lie will hardly compete for cognitive resources. Of course, there is no definitive basis to privilege the competing hypothesis just described. The prediction is also largely a conjecture. Nonetheless, answering the research questions brought to light will help clarify whether the presumed burden of morally justifying lies licenses cognitive load lie detection.

A critic may object to the issues just raised on the following grounds. The present rationale of cognitive load lie detection has nothing to do with liars contending the moral legitimacy of their lies. Such a critique will have to demonstrate why the current rationale consistently cites Levine et al. (2010), which explicitly aimed to empirically examine Bok's (1999) musings. Now, for argument's sake, let us entertain 
the potential objection. Assume the rationale intends to claim that motives play a significant role in deploying lies. That is, "[people] lie because they are too embarrassed to tell the truth (psychological reasons) or they lie to make money or to avoid punishment (material reasons) (Vrij, 2014, 2015)." Because liars have to consider those motives, lying is prone to becoming difficult; consequently, imposing cognitive load will expose lies.

Why such motives make lying versus truth-telling more liable to become cognitively demanding remains unclear. As Levine et al. (2010) indicate, people lie when their motives make truth-telling more challenging; for instance, when the truth might bring unwanted consequences. Remember that the interviewer does not know the would-be liar or truth-teller beforehand. Suppose lying, in that case, is an easier response option than truth-telling. Then the idea that motives make lying prone to difficulty contradicts the premise that engendered the idea. Furthermore, note that liars and truth-tellers arguably share the same motive to be believed, given the consequences of appearing dubious in an investigative interview. The reasons for wanting to be believed might vary. Future research must specify whether such lowerlevel variation exerts an important difference on the higher-order motive of wanting to be believed. For example, do the lower-level variations lead liars to want to be believed more than truth-tellers do? If such a difference exists, theorists must clarify how that difference makes imposing more cognitive load likely to expose lies. Then 
analysts can examine whether that presumed challenge is something interviewers can utilize to expose lies.

Another objection could be that the claim-lying requires a justification, and truth-telling does not-refers to answering unanticipated follow-up questions. Such a view supposes that liars versus truth-tellers will struggle more with justifying or answering follow-up questions to prove the plausibility of their false statements. There are two critical limitations with the hypothesis just described. First, it is unclear why liars would be more susceptible to needing a justification for their messages. An interviewer might well ask truth-tellers probing questions too. Again, remember that the interviewer does not know the would-be honest person beforehand. As I have argued previously, we cannot take it for granted that unexpected questions present truth-tellers versus liars an easier hurdle. Exponents must first specify the concomitant definitions and mechanisms of what unanticipated questions generally constitute.

The second limitation arises when considering the probing effect (e.g., Levine \& McCornack, 1996). Studies have shown that probing questions make liars and truthtellers appear honest (Buller et al., 1989; Levine \& McCornack, 2001). Thus, whatever difficulty follow-up questions might invite, interviewees seem to rise to the challenge; probing hampers lie detection, not improve it. When researchers outline a theory of what generally constitutes unanticipated questions, it may be worth reexamining the probing effect using the specified unanticipated questioning method. Such research will 
clarify how answering unexpected follow-up questions warrants the cognitive load lie detection premise.

\section{Suppression of the Truth}

Another justification of cognitive load lie detection is the claim that liars must suppress the truth while lying; exponents assert that such suppression is straining on liars (e.g., Leal et al., 2008; Vrij, 2015). Two strands of support often accompany that assertion. One strand comprises of neuroimaging studies that have examined the brain regions involved in lying (viz., Christ et al., 2009; Spence et al., 2001; Spence \& KaylorHughes, 2008). Taken together, those neuroimaging studies generally reveal that lying recruits brain regions responsible for executive control, inhibitory control, task switching, and working memory. The other source of support comes from a study that examined how frequent lying or truth-telling subsequently influences the difficulty of performing the same behaviors (Verschuere et al., 2011). Next, I will critically analyze the idea that liars must suppress the truth while lying, the notion that such suppression is taxing, and the evidence cited to support the idea.

Let us begin by trying to decipher what the phrase suppression of the truth means. One possible interpretation is that the phrase suppression of the truth is synonymous with lying; the phrase simply means not telling the truth. The current interpretation leaves the pressing questions unanswered. What the presumed suppression is remains unknown. Exponents must define how suppression differs from 
lying and specify how that difference makes lying versus truth-telling more challenging such that one can capitalize on suppression to expose lies.

One may object to the limitation just described by contending that the analysis is overly simplistic. Critics might argue that people lie using a myriad of strategies that warp the truth in different ways. For example, liars may partially distort the truth, fabricate similar versions of the truth, or feign amnesia. Thus, suppression of the truth features in different ways depending on the chosen strategy. For that argument's sake, assume that suppressing the truth is not synonymous with lying. Then the next available interpretation is this: suppression is a separate behavior the liar performs in addition to whatever strategy they choose as a means of communicating their lie. Two critical research questions become evident. First, what specific behavior, during lying, constitutes suppression, and does that behavior change depending on the strategy chosen as the preferred method of lying? Second, how do such behaviors make lying more laborious than truth-telling?

Let us consider a possible solution to the issues just outlined. One might propose that suppression constitutes a liar physically preventing themselves from communicating the requested truth before communicating a lie. Arguably, such a feat will be more challenging than simply communicating the truth, which requires no hesitation. That a would-be truth-teller can communicate a requested truth with no hesitation is a tenuous claim. Following conversational norms (Grice, 1975), a truthteller might need a moment to ascertain, for example, the version of the truth that 
best answers a question. Suppose a liar prepares their lies in advance. In that case, the so-called suppression mechanism is unlikely to feature; the liar already knows what they intend to say. Hence, the suppression mechanism could occur only when the question is unexpected. Previously, I have broached specification issues with the theory surrounding unanticipated questions; but there are more limitations to raise here.

The neuroimaging studies cited to support suppression suggest that lying involves inhibitory control and task switching (see, e.g., Christ et al., 2009). However, those studies do not indicate that liars necessarily inhibit the truth or switch their response from a truth to a lie. Liars might well be inhibiting/switching over irrelevant information, implausible lies, or inconsistent messages that may damage their goal. The results of Walczyk et al. (2003, Experiment 1) illustrate my contention. In that study, people reported the thoughts that occurred to them when lying to open-ended questions. Of those reports, $35.3 \%$ related to the requested truth and an approximately equal amount, $34.93 \%$, related to other possible responses (p. 765). Furthermore, based on Gricean norms, one can reasonably expect that truth-tellers might also inhibit what they consider irrelevant information, given a receiver's inquiry. A question that needs answering here is whether liars and truth-tellers experience different levels of intrusive thoughts when communicating in investigative interviews. Then it must be ascertained whether that feature corresponds to different levels of cognitive load, which can be exploited to expose lying. 
Spence and Kaylor-Hughes (2008) theorize about a specific instance in which people might physically prevent themselves from uttering the truth before telling a lie. In that scenario, the truthful response to a question is yes, and the liar has a limited time to lie by saying no- or vice versa. Spence and Kaylor-Hughes (2008) posit that those conditions mentally prompt the word yes to the extent that the liar must stop themself from saying yes before saying no. Even if one grants that proposition, the depicted scenario is highly narrow considering the possible range of responses in an investigative interview and conversations in general. Additionally, there is the practical matter; how does a receiver reliably flag whether a yes- or no-response was slow enough to suggest that the sender spent the time inhibiting the alternative response? Verschuere et al. (2011) was also a yes- or no-response format study whose findings demonstrate that practice makes people fluent liars. In all, these research works hardly offer evidence of a thought suppression mechanism specifically inducing cognitive load that one can exploit.

There is another species of evidence one can leverage as support for the idea that suppression constitutes a liar physically preventing themselves from communicating the requested truth before communicating a lie. That is, research about the cognitive consequences of secrecy: Lane and Wegner (1995) theorized that people become mentally preoccupied with thoughts about topics they want to keep secret. The corresponding empirical studies supported the theory; secrecy invites intrusive thoughts about topics people want to conceal (Lane \& Wegner, 1995). If lying 
comprises an attempt to conceal something, call that thing item- $i$, item- $i$ could behave like a secret. Then a liar would be mentally preoccupied with item- $i$ to the extent that the liar might have to physically prevent themself from blurting out item- $i$ while communicating the intended lie.

Lane and Wegner (1995, p. 238) explicitly noted that lying by commission recruits a different mechanism from the preoccupation model of secrecy they propose. A person will likely be preoccupied with thoughts of item- $i$ when the person has nothing to say in place of item- $i$. "Unlike lying [emphasis added], secrecy suggests 'no distracters' to stand in for the omitted information, and so leaves the secret keeper with nothing to think about but the secret itself (Lane \& Wegner, 1995, p. 238)." Thus, when the liar thinks of or has something to say in place of item- $i$, preoccupation with item- $i$ is not necessarily likely to feature. Let us briefly grant the unwarranted concession that liars might be so preoccupied with item- $i$ that item- $i$ would become mentally intrusive and labor lying. Item- $i$ is likely to vary on several dimensions depending on the interviewer's inquiry, for example, the complexity of item- $i$ and when item- $i$ occurred relative to the inquiry. Hence, an objection that invokes the preoccupation model of secrecy despite its limitations in accounting for the suppression mechanism must answer two research questions. First, that objection must reconcile their proposition with the caveats Lane and Wegner (1995, p. 238) describe. Then the exponents must offer a wieldy taxonomy of item- $i$ and explain how the constituents of that taxonomy elicit cognitive load during suppression. 
To summarize, whatever liars supposedly suppress, one cannot be certain that liars become preoccupied with that thing. Or that liars physically prevent themselves from uttering the truth being requested before relaying a lie. The claim that liars must suppress the truth while lying belies an elusive mechanism that remains to be verified. Importantly, we cannot take it for granted that the presumed suppression burdens liars' cognitive resources such that the suppression justifies cognitive load lie detection.

\section{The Activation of Truths and Lies}

Authors have proposed that the activation of a lie is deliberate, whereas the truth comes to mind automatically. The proponents argue that such a difference in automaticity makes lying more liable to mental effort than truth-telling, warranting cognitive load lie detection (e.g., Leal \& Vrij, 2008; Vrij, 2015; Vrij \& Ganis, 2014).

Suppose a liar knows the prospective topics to be discussed and prepares possible lies in advance. In that case, activation will not likely be at issue. The lie is already in mind. Thus, activation might be problematic for liars when they encounter unexpected questions. Previously, I have noted that researchers must systematically delineate a theory of unanticipated questions. Such a theory should provide enough specification to license unanticipated questioning as an unambiguous lie detection method. For now, let us assume that there are themes of questions people generally do not expect. Why truth-tellers versus liars will more easily activate answers tailored to questions they do not anticipate remains unclear. At bottom, an unexpected question should be one that will predominantly lead any prospective respondent to ponder their 
would-be answers, especially given the risk of appearing dubious in an investigative interview. I have already discussed the limitation with assuming that truth-tellers will have an easier time conjuring plausible and consistent responses to unanticipated questions. Nonetheless, one could claim that the contention of interest remains unaddressed. Despite the need to ponder a response to an unexpected question, are truths more automatically mentally activated than lies? To answer that question, let us turn our attention to the evidence cited to support the idea that activation makes lying versus truth-telling more difficult, namely Gilbert (1991) and Walczyk et al. (2003).

Gilbert's (1991) exposition raises the sentiment that humans streamline their communication using the convention that incoming messages are generally truthful. It is not immediately apparent why authors cite Gilbert (1991) as support for the current justification. Future research can elucidate the necessary connection. Researchers assume that higher levels of cognitive load elicit longer reaction times. Walczyk et al. (2003) report specific conditions wherein the mental activation of lies versus truths elicited longer reaction times (and, by extension, more cognitive load). First, respondents were instructed to answer unexpected questions quickly. Second, the questions aimed to elicit short answers, namely, one- or two-word responses. As Walczyk et al. (2003) note, their findings offer a promising start, but, admittedly, the context they examined is narrow. It remains to be verified whether those results generalize to investigative interviews in which inquiries call for more than one- or two- 
word responses. Moreover, constraining interviewees to hasty answers is arguably impractical. It behooves future research to explore whether mentally generating narratives to unexpected questions presents a steeper challenge to liars versus truthtellers. Then we must ascertain whether one can exploit that hurdle to expose lies.

--insert Table 1 about here--

\section{Summary}

One may object to the thesis of the article thus far on the following basis. Granted, the seminal proposals of cognitive load lie detection usually offer the seven justifications (e.g., Leal et al., 2008; Vrij, 2015). Grant again, for argument's sake, that those justifications suffer limitations. The justifications remain underspecified such that, currently, analysts cannot falsify the foundation of cognitive load lie detection: that imposing cognitive load can expose lies.

Considering Vrij and Granhag (2012), however, at least a decade of research has studied the topic and created various cognitive load interventions to detect lies. Perhaps those articles and their proposed cognitive load interventions contain further justifications besides the limited seven: hopefully, justifications one can falsify. A systematic review may reveal those undiscovered justifications and potentially demonstrate two essential things: (a) that cognitive load lie detection rests on firm auxiliaries; and (b) that researchers hardly take the idea of cognitive load lie detection for granted. To address the issue of undiscovered justifications and the promise they might hold, I conducted a systematic descriptive review. 


\section{A Thematic Review in Search of Undiscovered Justifications}

The review relied on the same data used in the meta-analysis by Mac Giolla and Luke (2021). The interested reader can consult that publication for exhaustive details about the search strategy and inclusion criteria. I chose to use the data curated by Mac Giolla and Luke (2021) due to four reasons. (a) To my knowledge, that metaanalysis is currently the most recent one on cognitive load lie detection; (b) the authors included studies missed by the penultimate meta-analysis on the topic (viz., Vrij, Fisher, et al., 2017); (c) Mac Giolla and Luke (2021) selected studies of utmost applied relevance wherein observers made dichotomous lie detections as opposed to judging the extent of a statement's veracity; (d) by deferring the data curation to others, I hoped to exercise maximum objectivity over the inclusion and exclusion of studies. In all, the entire text of 24 publications were reviewed ${ }^{3}$.

\section{Method: Extracting the Components of the Review}

The review extracted four aspects of the selected studies to explore the current question of interest. The extraction protocol was preregistered beforehand (osf.io/8hjsk). The first component was whether a publication explicitly invoked Zuckerman et al.'s (1981) assertion that lying demands more cognitive resources than truth-telling does. The second item comprised explicit or implied invocations of the cognitive load lie detection foundational premise (e.g., Vrij \& Granhag, 2012). This

\footnotetext{
${ }^{3}$ One article, Zimmerman et al. (2010), could not undergo the review because that study is a classified report, which prevents analysis of the text
} 
category also included renditions without explicit citations. I identified such renditions in two ways (i) by flagging relevant sentences that appeared after authors quoted Zuckerman et al. (1981); or (ii) via compound sentences consisting of the Zuckerman et al. (1981) assertion, explicitly cited, followed by claims akin to the cognitive load premise (e.g., Vrij \& Granhag, 2012).

The third component flagged the authors' intervention of cognitive load, for example, unanticipated questions. The fourth item consisted of explanations that indicate why the authors chose the intervention(s) they did. That is, the reason(s) why the authors hypothesized that the intervention(s) they chose would enhance cognitive load and consequently lie detection. Such reasons are different from stating the premise of cognitive load lie detection. Those reasons specify the underlying mechanism or a justification of the intervention. Finally, I extracted the lie detection cues and the corresponding operationalizations in each publication. Lie detection cues are not pertinent to the current review but was included to provide a comprehensive database for further research. Table 2 contains the data extracted for the present review.

\section{Analysis Strategy}

The analysis strategy was fairly straightforward. The aim was to identify the frequency with which authors implicitly or explicitly invoked the cognitive load premise via seminal works, for example, Vrij and Granhag (2012) or Zuckerman et al. (1981). Next, I examined the frequency with which authors specified underlying mechanisms to justify those invocations and the corresponding cognitive load 
intervention. Then the analysis explored any themes evident in the flagged justifications.

The analysis largely followed the recommendations of Braun and Clarke (2006) on executing thematic reviews. I first read over the extracted data to get familiar with it and developed initial codes representing the data's contents. This initial coding phase revealed that authors typically employed varying formulations of the previously described seven justifications to support invocations of the cognitive load approach and cognitive load interventions. Moreover, each of the seven justifications appeared with different frequencies across invocations and interventions. Because the seven justifications already serve as interpretive attributes in the literature, I retained them as themes. The entire dataset was then compared again to the delineated attributes to ensure correspondence and identify any undiscovered justifications.

\section{Plausibility and Consistency (J1)}

This designation captures justifications suggesting that liars must monitor their lies to remain plausible and consistent. An example of such a justification is the claim that liars must ensure that what they report is plausible given the available information and those an interviewer can discover (i.e., Evans et al., 2013, p. 34).

Concern about Credibility (J2)

This category encapsulates justifications wherein authors assert that liars versus truth-tellers are less likely to take their credibility for granted. For instance, 
Warmelink et al. (2012, p. 178) write that "liars pay more attention to their credibility, which truth-tellers take for granted".

\section{Monitoring Success (J3)}

This theme contains justifications alluding to the notion that liars versus truthtellers monitor receivers' reactions to evaluate whether the receiver believes the lie. An example is the claim by Vernham et al. (2014, p. 310) that liars scrutinize the interviewer to check whether the lie is being believed, whereas truth-tellers merely focus on storytelling.

\section{Preoccupation with Role-play (J4)}

Here, I grouped justifications wherein authors indicate that liars may be engrossed in playing the role of the truth-teller. As such, this category included assertions that liars versus truth-tellers are more concerned with impression management (e.g., Collwell et al., 2015).

\section{The Basis for Lying (J5)}

This designation contains verbatim claims that lying requires a justification, but truth-telling does not (see, e.g., Vrij et al., 2008).

\section{Suppression of the Truth (J6)}

This category included justifications stating that liars have to suppress or inhibit the truth; for example, their actual memory of an event or information (e.g., Evans \& Michael, 2014) 


\section{Mental Activation of Truths and Lies (J7)}

This theme comprised justifications implying that the mental activation of a lie is deliberate, whereas the truth comes to mind automatically. Examples include the claim that mnemonic devices like context reinstatement improve truth-tellers' recall but raise the cognitive effort required to lie (i.e., Montavlo et al., 2013). And Leins et al.'s (2017) assertion that truth-tellers can produce a reverse order narrative, from memory, with relative ease, but lying requires a novel construction.

\section{No justification (NJ)}

Some invocations of the cognitive load premise and interventions of cognitive load included no justifications. Such instances received the no justification category.

\section{Foundational Premise of the Cognitive Load Approach (FP)}

Some authors justified their interventions of cognitive load by restating the foundational premise of cognitive load lie detection. Those justifications received the current classification. An example is the claim that liars versus truth-tellers will find it more difficult to produce their message in a second language because honesty versus truth-telling is not particularly challenging (i.e., Evans \& Michael, 2014) --insert Table 2 about here--

\section{Results and Discussion}

Figures 1 and 2 illustrate the frequency of justifications (J1 through J7) across the invocations of the cognitive load premise and cognitive load interventions, 
respectively. The interested reader may consult the supplemental table in the appendix, which depicts the thematic analysis in exhaustive detail. One can use the supplemental table to reproduce the results.

\section{Invocations of the Cognitive Load Premise}

The findings indicated that few research works ascribe the idea of cognitive load lie detection to Zuckerman et al. (1981), although seminal works suggest Zuckerman et al. (1981) engendered cognitive load lie detection (e.g., Vrij, 2008; 2015). Most publications, $87.5 \%(21 / 24)$, invoked the cognitive load premise by explicitly citing at least one seminal publication on the topic or implied the premise without an explicit citation. Implicit invocations, $41.66 \%$ (10/24), contained a handful of justifications: seven of ten publications offered no justification when implying that cognitive load can improve lie detection (see Figure 1). Of the three invocations with justifications, Vrij et al. (2010) advanced J1 through J7; Fenn (2015) offered J7, and Evans et al. (2013) offered J1, J6, and J7. Explicit invocations, 45.83\% (11/24), included more justifications than implied invocations (see Figure 1). Three of those explicit invocations came with no justification, but the remaining eight contained at least one reason justifying the cognitive load premise.

Notably, there appeared to be no systematic way by which justifications J1 through J7 were applied. Authors recycled the common list of seven justifications across the implicit and explicit invocations of the premise that cognitive load can expose lies (see Table 2 or the supplemental table). 


\section{Figure 1}

Invocations of the Cognitive Load Premise

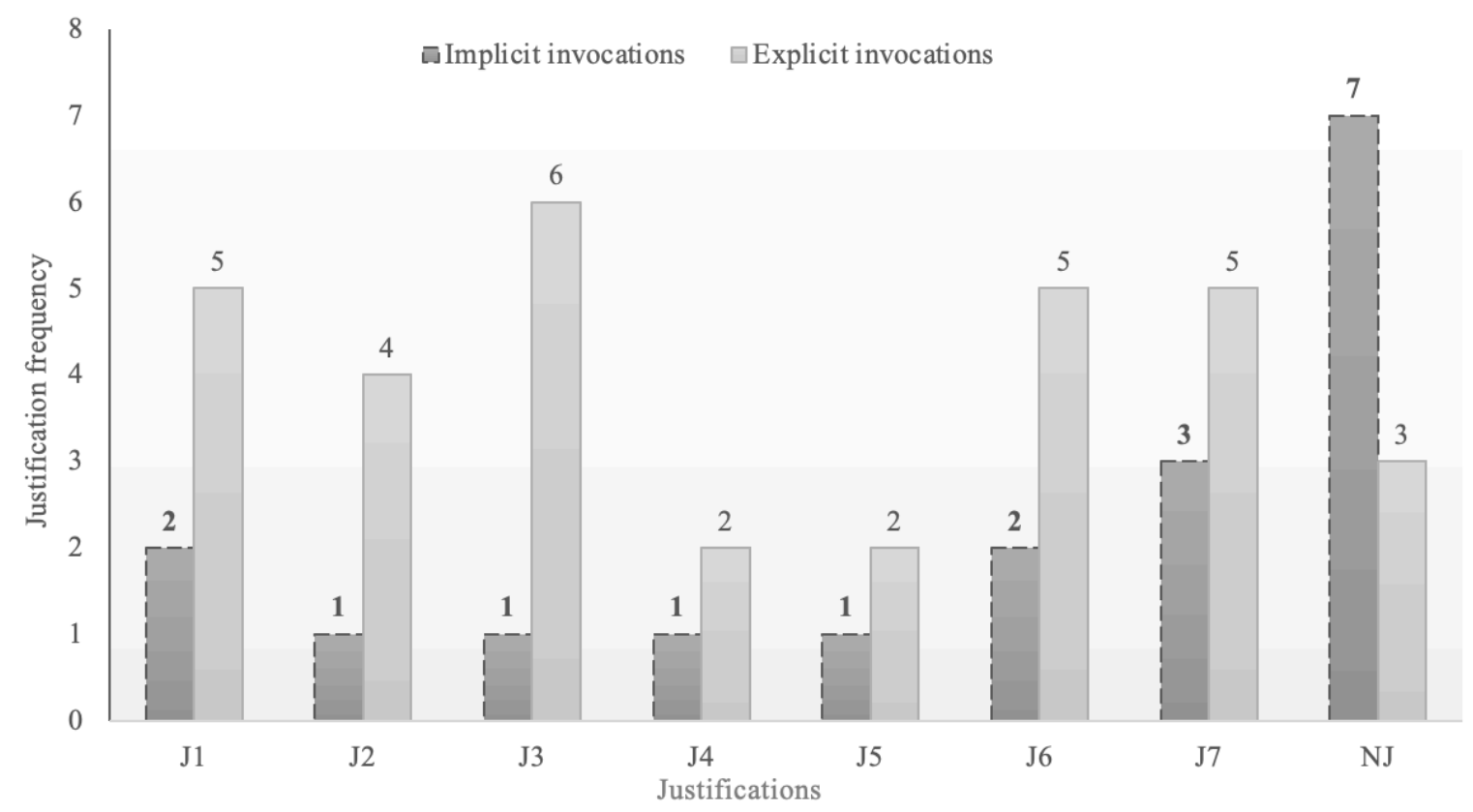

\section{Cognitive Load Interventions}

Based on the authors' descriptions, nine distinct interventions (i.e., training programs and manipulations) of cognitive load lie detection emerged from the dataset. The training programs were: (a) the Assessment Criteria Indicative of Deception (ACID); (b) general training in cognitive load lie detection; and (c) the cognitive interview for suspects (CIS). The manipulations included requiring interviewees to: (d) communicate in a nonnative language; (e) maintain eye contact with their interviewer; (f) perform a secondary task while communicating; (g) argue against their opinion (devil's advocate); (h) provide reverse chronological reports; and (i) answer unanticipated questions. The ambiguous nature of what constitutes an unanticipated 
question became evident when flagging the interventions (see Figure 2). For example, some publications described reverse chronological reports as likely to be unanticipated (e.g., Geiselman, 2012), whereas other publications distinguished reverse reporting from unanticipated questions (Leins et al., 2017).

Eight interventions (excluding the CIS) came with at least one of the familiar seven justifications. However, those justifications appeared with considerable variance and in no systematic manner (see Figure 2). Notably, six primary interventions were justified at least once by authors restating the foundational premise of cognitive load lie detection, which belies a tautological justification. Stating that an interviewer will expose lies because an intervention will be challenging for liars fails to explain how that intervention exerts the hypothesized influence. Owing to the cognitive load premise, any intervention classified as a cognitive load technique should make lying difficult by default. Thus, cognitive load interventions must critically outline the processes that engender their difficulty. 


\section{Figure 2}

Cognitive Load Interventions and their Justifications

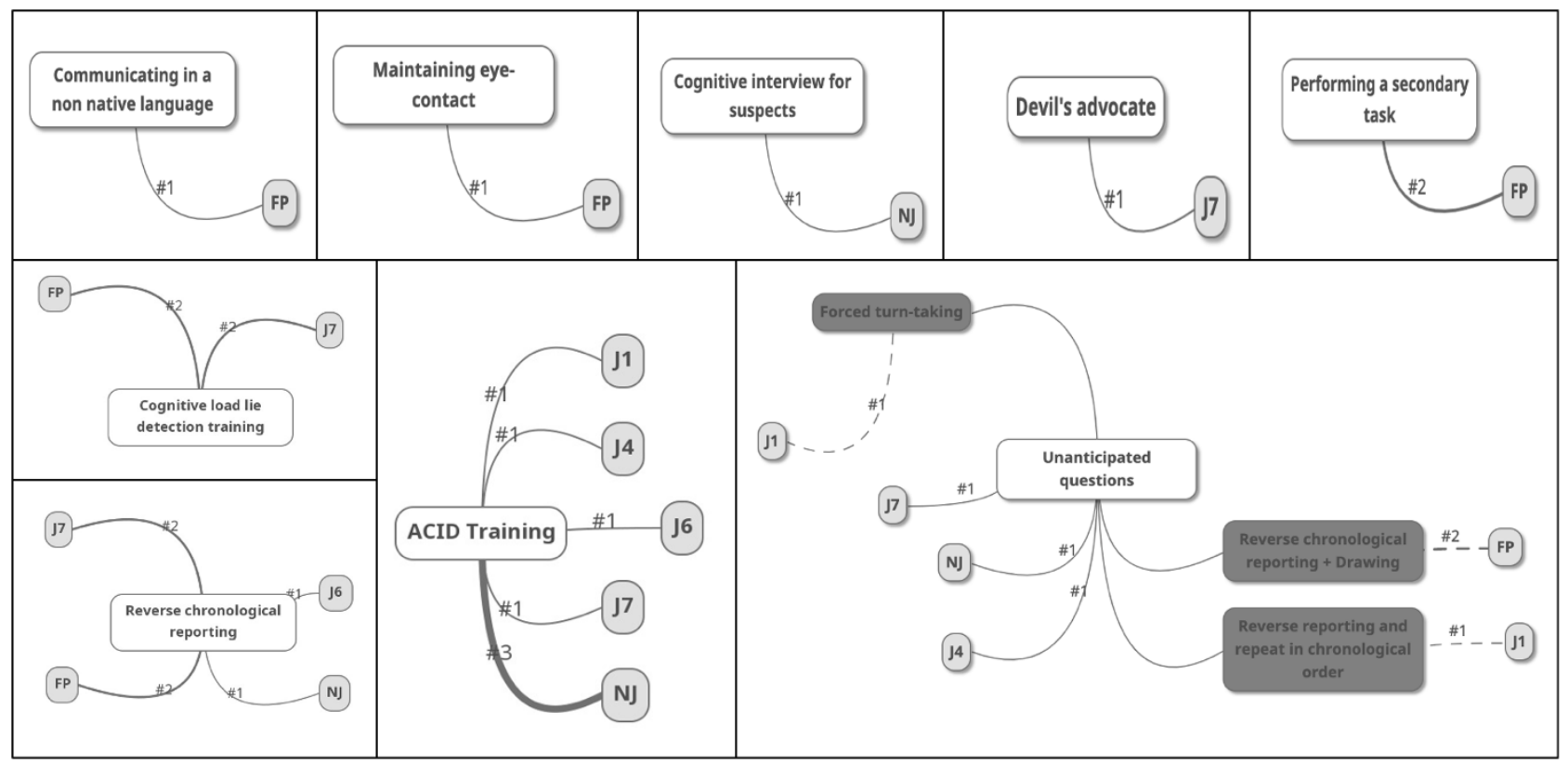

Note. Thicker branches indicate a higher frequency of a justification

\section{Summary}

The thematic analysis set out to find undiscovered justifications of cognitive load lie detection, besides the well-known seven. Overall, the findings indicate that authors recycle the familiar seven justifications, despite their limitations, to support invocations of the cognitive load premise and cognitive load interventions. Presently, authors largely seem to take the notion of cognitive load lie detection for granted. The prevailing assumption seems to be that any of the customary seven justifications offers a firm auxiliary on which one can stake their research. Authors currently invest minimal effort addressing whether striving to detect lies via cognitive load is, indeed, 
a productive path to ply from a theoretical and applied perspective (but see Fenn et al., 2015 and Walczyk et al., 2013).

Critics might object by claiming that perhaps the issues this article raises only feature because the publications reviewed here belong to a peculiar list (i.e., Mac Giolla \& Luke, 2021). Undiscovered justifications might well exist, and the objector might cite them. For argument's sake, let us concede to that hypothetical objection and its presumed evidence. Still, the present work indicates that the literature substantially relies on the customary seven justifications. Stakeholders should be concerned that the theoretical fitness of those seven justifications remain variable and unknown.

\section{Where Should We Go from Here?}

This review of justifications indicates that the critical limitation remains outstanding. Cognitive load lie detection largely rests on a collection of theoretically ambiguous auxiliaries that analysts cannot currently falsify even if analysts try. Many publications have taken the cognitive load lie detection premise as a given and assume the idea rests on firm ground when there are cracks in the foundation. Moreover, it remains unclear which of the seven justifications primarily vitalizes the cognitive load lie detection premise. Even if an analyst were to present evidence to reject one justification, the rejection could simply be explained away by shifting to another justification to preserve the claim that the cognitive load lie detection premise remains robust. The literature must rid itself of that problematic loophole. 
The way forward is to better specify each justification to allow falsification. Such efforts will help determine the justifications that can serve as firm auxiliaries and potential boundary conditions under which those auxiliaries hold. For example, do the justifications hold early or later in interviews; or do the justifications hold only when truth-tellers versus liars fail to grasp the potential risks an investigative interview brings? Do the justifications hold over multiple interviews? Currently, exponents do not specify boundary conditions for any of the justifications. Table 1 provides a list of research avenues to commence the process of reexamining the justifications. Luke (2019) also offers critical methodological reforms.

The present state of the literature does not mean we should reject cognitive load lie detection outright. Let us not throw a potential baby out with the bathwater, but we must ensure that there is, indeed, a baby in the bathwater. Stakeholders must revisit the drawing board and iron out the foundations of cognitive load lie detection. 
References

References marked with an asterisk* were included in the thematic review.

Blandón-Gitlin, I., Fenn, E., Masip, J., \& Yoo, A. H. (2014). Cognitive-load approaches to detect deception: Searching for cognitive mechanisms. Trends in Cognitive Sciences, 18(9), 441-444.

https://doi.org/10.1016/j.tics.2014.05.004

Bok, S. (1999). Lying: Moral Choice in Public and Private Life. Vintage.

Braun, V., \& Clarke, V. (2006). Using thematic analysis in psychology. Qualitative Research in Psychology, 3(2), 77-101.

https://doi.org/10.1191/1478088706qp063oa

Buller, D. B., \& Burgoon, J. K. (1996). Interpersonal Deception Theory. Communication Theory, 6(3), 203-242. https://doi.org/10.1111/j.1468$\underline{2885.1996 . t b 00127 . x}$

Buller, D. B., Comstock, J., Aune, R. K., \& Strzyzewski, K. D. (1989). The effect of probing on deceivers and truthtellers. Journal of Nonverbal Behavior, 13(3), 155-170. https://doi.org/10.1007/BF00987047

Christ, S. E., Van Essen, D. C., Watson, J. M., Brubaker, L. E., \& McDermott, K. B. (2009). The Contributions of Prefrontal Cortex and Executive Control to Deception: Evidence from Activation Likelihood Estimate Meta-analyses. Cerebral Cortex, 19(7), 1557-1566. https://doi.org/10.1093/cercor/bhn189 
Colwell, K., Hiscock-Anisman, C. K., Memon, A., Taylor, L., \& Prewett, J. (2007). Assessment Criteria Indicative of Deception (ACID): An integrated system of investigative interviewing and detecting deception. Journal of Investigative Psychology and Offender Profiling, 4(3), 167-180.

https://doi.org/10.1002/jip.73

Colwell, K., Hiscock-Anisman, C., \& Fede, J. (2013). Assessment Criteria Indicative of Deception: An Example of the New Paradigm of Differential Recall Enhancement. In B. S. Cooper, D. Griesel, \& M. Ternes (Eds.), Applied Issues in Investigative Interviewing, Eyewitness Memory, and Credibility Assessment (pp. 259-291). Springer. https://doi.org/10.1007/978-1-4614-5547-9 11

*Colwell, K., Hiscock-Anisman, C., Memon, A., Colwell, L. H., Taylor, L., \& Woods, D. (2009). Training in Assessment Criteria Indicative of Deception to Improve Credibility Judgments. Journal of Forensic Psychology Practice, 9(3), 199207. https://doi.org/10.1080/15228930902810078

*Colwell, K., James-Kangal, N., Hiscock-Anisman, C., \& Phelan, V. (2015). Should Police Use ACID? Training and Credibility Assessment Using Transcripts Versus Recordings. Journal of Forensic Psychology Practice, 15(3), 226-247. https://doi.org/10.1080/15228932.2015.1035187

*Colwell, L. H., Colwell, K., Hiscock-Anisman, C. K., Hartwig, M., Cole, L., Werdin, K., \& Youschak, K. (2012). Teaching Professionals to Detect Deception: The 
Efficacy of a Brief Training Workshop. Journal of Forensic Psychology

Practice, 12(1), 68-80. https://doi.org/10.1080/15228932.2012.629592

DePaulo, B. M., Lindsay, J. J., Malone, B. E., Muhlenbruck, L., Charlton, K., \& Cooper, H. (2003). Cues to deception. Psychological Bulletin, 129(1), 74-118. https://doi.org/10.1037/0033-2909.129.1.74

*Evans, J. R., \& Michael, S. W. (2014). Detecting Deception in Non-Native English Speakers: Detecting deception in non-native speakers. Applied Cognitive Psychology, 28(2), 226-237. https://doi.org/10.1002/acp.2990

*Evans, J. R., Michael, S. W., Meissner, C. A., \& Brandon, S. E. (2013). Validating a new assessment method for deception detection: Introducing a Psychologically Based Credibility Assessment Tool. Journal of Applied Research in Memory and Cognition, 2(1), 33-41.

https://doi.org/10.1016/j.jarmac.2013.02.002

Frank, A., Biberci, S., \& Verschuere, B. (2019). The language of lies: A preregistered direct replication of Suchotzki and Gamer (2018; Experiment 2). Cognition and Emotion, 33(6), 1310-1315.

https://doi.org/10.1080/02699931.2018.1553148

*Fenn, E. (2015). Social contexts for detecting deception: Factors that moderate the effectiveness of cognitive load approach interviews. Doctoral dissertation, The Claremont Graduate University. 
*Fenn, E., McGuire, M., Langben, S., \& Blandón-Gitlin, I. (2015). A reverse order interview does not aid deception detection regarding intentions. Frontiers in Psychology, 6. https://doi.org/10.3389/fpsyg.2015.01298

*Geiselman, R. E. (2012). The cognitive interview for suspects (CIS). American Journal of Forensic Psychology, 30(3), 5-20.

Gilbert, D. T. (1991). How mental systems believe. American Psychologist, 46(2), 107-119. https://doi.org/10.1037/0003-066X.46.2.107

Gilovich, T., Savitsky, K., \& Medvec, V. H. (1998). The illusion of transparency: Biased assessments of others' ability to read one's emotional states. Journal of Personality and Social Psychology, 75(2), 332-346.

https://doi.org/10.1037/0022-3514.75.2.332

Granhag, P., A. \& Hartwig, M. (2015). The Strategic Use of Evidence Technique: A Conceptual Overview. In A. Vrij \& B. Verschuere (Eds.), Deception detection: Current challenges and new directions (pp. 231-251). John Wiley \& Sons, Ltd. https://doi.org/10.1002/9781118510001.ch10

Granhag, P. A., \& Strömwall, L. A. (2002). Repeated interrogations: Verbal and non-verbal cues to deception: Verbal and non-verbal cues to deception. Applied Cognitive Psychology, 16(3), 243-257.

https://doi.org/10.1002/acp.784 
Hartwig, M., Anders Granhag, P., \& Strömwall, L. A. (2007). Guilty and innocent suspects' strategies during police interrogations. Psychology, Crime $\&$ Law, 13(2), 213-227. https://doi.org/10.1080/10683160600750264

*Jordan, S. (2016). The Effect of Cognitive Load on Liars and Truth Tellers: Exploring the Moderating Impact of Working Memory Capacity. Graduate Center, City University of New York.

Lane, J. D., \& Wegner, D. M. (1995). The cognitive consequences of secrecy. Journal of Personality and Social Psychology, 69(2), 237-253. http://dx.doi.org.ezproxy.ub.gu.se/10.1037/0022-3514.69.2.237

Leal, S., \& Vrij, A. (2008). Blinking During and After Lying. Journal of Nonverbal Behavior, 32(4), 187-194. https://doi.org/10.1007/s10919-008-0051-0

Leal, S., Vrij, A., Fisher, R. P., \& van Hooff, H. (2008). The time of the crime: Cognitively induced tonic arousal suppression when lying in a free recall context. Acta Psychologica, 129(1), 1-7. https://doi.org/10.1016/j.actpsy.2008.03.015

*Leal, S., Vrij, A., Mann, S., \& Fisher, R. P. (2010). Detecting true and false opinions: The Devil's Advocate approach as a lie detection aid. Acta Psychologica, 134(3), 323-329. https://doi.org/10.1016/j.actpsy.2010.03.005

*Leins, D. A., Zimmerman, L. A., \& Polander, E. N. (2017). Observers' Real-Time Sensitivity to Deception in Naturalistic Interviews. Journal of Police and 
Criminal Psychology, 32(4), 319-330. https://doi.org/10.1007/s11896-017$\underline{9224-2}$

Leins, D., Fisher, R. P., Vrij, A., Leal, S., \& Mann, S. (2011). Using sketch drawing to induce inconsistency in liars. Legal and Criminological Psychology, 16(2), 253-265. https://doi.org/10.1348/135532510X501775

Lerner, M. J. (1998). The Two Forms of Belief in a Just World. In L. Montada \& M. J. Lerner (Eds.), Responses to Victimizations and Belief in a Just World (pp. 247-269). Springer US. https://doi.org/10.1007/978-1-4757-6418-5 13

Levine, T. R., \& McCornack, S. A. (2001). Behavioral Adaptation, Confidence, and Heuristic-Based Explanations of the Probing Effect. Human Communication Research, 27(4), 471-502. https://doi.org/10.1111/j.1468-2958.2001.tb00790.x

Levine, T. R., Blair, J. P., \& Carpenter, C. J. (2018). A critical look at metaanalytic evidence for the cognitive approach to lie detection: A re-examination of Vrij, Fisher, and Blank (2017). Legal and Criminological Psychology, 23(1), 7-19. https://doi.org/10.1111/lcrp.12115

Levine, T. R., Kim, R. K., \& Hamel, L. M. (2010). People Lie for a Reason: Three Experiments Documenting the Principle of Veracity. Communication Research Reports, 27(4), 271-285.

https://doi.org/10.1080/08824096.2010.496334 
Levine, T., \& McCornack, S. A. (1996). A Critical Analysis of the Behavioral Adaptation Explanation of the Probing Effect. Human Communication Research, 22(4), 575-588. https://doi.org/10.1111/j.1468-2958.1996.tb00380.x

*Liu, M., Granhag, P. A., Landström, S., Hjelmsaeter, E. R. A., Strömwall, L., \& Vrij, A. (2010). Can you remember what was in your pocket when you were stung by a bee?: Eliciting cues to deception by asking the unanticipated. Open Criminology Journal, 3(1), 31-36.

*Logue, M. (2017). Effective Police Interviewing [Psychology]. Brock University. Luke, T. J. (2019). Lessons From Pinocchio: Cues to Deception May Be Highly Exaggerated. Perspectives on Psychological Science, 14(4), 646-671. https://doi.org/10.1177/1745691619838258

Mac Giolla, E., \& Luke, T. J. (2021). Does the cognitive approach to lie detection improve the accuracy of human observers? Applied Cognitive Psychology, 35(2), 385-392. https://doi.org/10.1002/acp.3777

Mahon, J. E. (2008). Two Definitions of Lying. International Journal of Applied Philosophy, 22(2), 211-230. https://doi.org/10.5840/ijap200822216

McCornack, S. A. (1992). Information manipulation theory. Communication Monographs, 59(1), 1-16. https://doi.org/10.1080/03637759209376245

Meehl, P. E. (1990). Why Summaries of Research on Psychological Theories are Often Uninterpretable. Psychological Reports, 66(1), 195-244. https://doi.org/10.2466/pr0.1990.66.1.195 
*Montalvo, L., Hallinan, C., Hiscock-Anisman, C., Morrissey, D., Bonilla, Y., Colwell, K., \& Kradas, M. (2013). Using ACID to improve credibility assessments with written and audio statements. American Journal of Forensic Psychology, 31(2), 55-69.

Najdowski, C. J. (2011). Stereotype threat in criminal interrogations: Why innocent Black suspects are at risk for confessing falsely. Psychology, Public Policy, and Law, 17(4), 562-591. http://dx.doi.org.ezproxy.ub.gu.se/10.1037/a0023741

*Patterson, T. (2009). The Effect of Cognitive Load on Deception [Psychology, Florida International University]. https://doi.org/10.25148/etd.FI09120811 *Saykaly, C., Crossman, A., \& Talwar, V. (2017). High Cognitive Load During Cross-Examination: Does It Improve Detection of Children's Truths and Lies? Psychiatry, Psychology and Law, 24(2), 278-291. https://doi.org/10.1080/13218719.2016.1197816

Schafer, J. (2020, September). 3 Simple Techniques to Detect Deception | Psychology Today. Psychology Today. https://www.psychologytoday.com/us/blog/lettheir-words-do-the-talking/202009/3-simple-techniques-detect-deception

Scheel, A. M., Tiokhin, L., Isager, P. M., \& Lakens, D. (2021). Why Hypothesis Testers Should Spend Less Time Testing Hypotheses. Perspectives on Psychological Science, 16(4), 744-755.

https://doi.org/10.1177/1745691620966795 
Schlenker, B. R., \& Pontari, B. A. (2000). The strategic control of information: Impression management and self-presentation in daily life. In Psychological perspectives on self and identity (pp. 199-232). American Psychological Association. https://doi.org/10.1037/10357-008

Schweitzer, M. E., Brodt, S. E., \& Croson, R. T. A. (2002). Seeing and believing: Visual access and the strategic use of deception. International Journal of Conflict Management, 13(3), 258-375. https://doi.org/10.1108/eb022876

*Sooniste, T., Granhag, P. A., \& Strömwall, L. A. (2017). Training Police Investigators to Interview to Detect False Intentions. Journal of Police and Criminal Psychology, 32(2), 152-162. https://doi.org/10.1007/s11896-016$\underline{9206-9}$

Spence, S. A., \& Kaylor-Hughes, C. J. (2008). Looking for truth and finding lies: The prospects for a nascent neuroimaging of deception. Neurocase, 14(1), 68-81. https://doi.org/10.1080/13554790801992776

Spence, S. A., Farrow, T. F. D., Herford, A. E., Wilkinson, I. D., Zheng, Y., \& Woodruff, P. W. R. (2001). Behavioural and functional anatomical correlates of deception in humans: Neuroreport, 12(13), 2849-2853. https://doi.org/10.1097/00001756-200109170-00019 Sporer, S. L. (2016). Deception and Cognitive Load: Expanding Our Horizon with a Working Memory Model. Frontiers in Psychology, 7, 420. 
Strömwall, L. A., Hartwig, M., \& Granhag, P. A. (2006). To act truthfully:

Nonverbal behaviour and strategies during a police interrogation. Psychology,

Crime \&f Law, 12(2), 207-219. https://doi.org/10.1080/10683160512331331328

*Vernham, Z., Vrij, A., Mann, S., Leal, S., \& Hillman, J. (2014). Collective

interviewing: Eliciting cues to deceit using a turn-taking approach.

Psychology, Public Policy, and Law, 20(3), 309-324.

https://doi.org/10.1037/law0000015

Verschuere, B., Köbis, N. C., Bereby-Meyer, Y., Rand, D., \& Shalvi, S. (2018).

Taxing the Brain to Uncover Lying? Meta-analyzing the Effect of Imposing

Cognitive Load on the Reaction-Time Costs of Lying. Journal of Applied

Research in Memory and Cognition, 7(3), 462-469.

https://doi.org/10.1016/j.jarmac.2018.04.005

Verschuere, B., Spruyt, A., Meijer, E. H., \& Otgaar, H. (2011). The ease of lying.

Consciousness and Cognition, 20(3), 908-911.

https://doi.org/10.1016/j.concog.2010.10.023

Vohs, K. D., \& Baumeister, R. F. (2016). Handbook of Self-Regulation, Third

Edition: Research, Theory, and Applications. Guilford Publications.

Vrij, A. (2019). Deception and truth detection when analyzing nonverbal and verbal cues. Applied Cognitive Psychology, 33(2), 160-167.

https://doi.org/10.1002/acp.3457 
Vrij, A. (2008). Detecting Lies and Deceit: Pitfalls and Opportunities. John Wiley \& Sons.

Vrij, A. (2014). Interviewing to detect deception. European Psychologist, 19(3), 184194. http://dx.doi.org.ezproxy.ub.gu.se/10.1027/1016-9040/a000201

Vrij, A. (2015). A cognitive approach to lie detection. In Detecting deception: Current challenges and cognitive approaches (pp. 205-229). Wiley-Blackwell.

Vrij, A., \& Ganis, G. (2014). Theories in Deception and Lie Detection. In D. C. Raskin, C. R. Honts, \& J. C. Kircher (Eds.), Credibility Assessment (pp. 301374). Academic Press. https://doi.org/10.1016/B978-0-12-394433-7.00007-5

Vrij, A., \& Granhag, P. A. (2012). Eliciting cues to deception and truth: What matters are the questions asked. Journal of Applied Research in Memory and Cognition, 1(2), 110-117. https://doi.org/10.1016/j.jarmac.2012.02.004

Vrij, A., \& Granhag, P. A. (2014). Eliciting Information and Detecting Lies in Intelligence Interviewing: An Overview Of Recent Research. Applied Cognitive Psychology, 28(6), 936-944. https://doi.org/10.1002/acp.3071

Vrij, A., Blank, H., \& Fisher, R. P. (2018). A re-analysis that supports our main results: A reply to Levine et al. Legal and Criminological Psychology, 23(1), 20-23. https://doi.org/10.1111/lcrp.12121

Vrij, A., Fisher, R. P., \& Blank, H. (2017). A cognitive approach to lie detection: A meta-analysis. Legal and Criminological Psychology, 22(1), 1-21. https://doi.org/10.1111/lcrp.12088 
Vrij, A., Fisher, R., Mann, S., \& Leal, S. (2006). Detecting deception by manipulating cognitive load. Trends in Cognitive Sciences, 10(4), 141-142. https://doi.org/10.1016/j.tics.2006.02.003

Vrij, A., Granhag, P. A., Mann, S., \& Leal, S. (2011). Outsmarting the Liars: Toward a Cognitive Lie Detection Approach. Current Directions in Psychological Science, 20(1), 28-32.

https://doi.org/10.1177/0963721410391245

Vrij, A., Leal, S., Granhag, P. A., Mann, S., Fisher, R. P., Hillman, J., \& Sperry, K. (2009). Outsmarting the Liars: The Benefit of Asking Unanticipated Questions. Law and Human Behavior, 33(2), 159-166.

https://doi.org/10.1007/s10979-008-9143-y

*Vrij, A., Leal, S., Mann, S. A., \& Granhag, P. A. (2011). A comparison between lying about intentions and past activities: Verbal cues and detection accuracy. Applied Cognitive Psychology, 25(2), 212-218.

https://doi.org/10.1002/acp.1665

Vrij, A., Leal, S., Mann, S., \& Fisher, R. (2012). Imposing cognitive load to elicit cues to deceit: Inducing the reverse order technique naturally. Psychology, Crime E Law, 18(6), 579-594. https://doi.org/10.1080/1068316X.2010.515987

*Vrij, A., Leal, S., Mann, S., Vernham, Z., \& Brankaert, F. (2015). Translating theory into practice: Evaluating a cognitive lie detection training workshop. 
Journal of Applied Research in Memory and Cognition, 4(2), 110-120.

https://doi.org/10.1016/j.jarmac.2015.02.002

*Vrij, A., Mann, S. A., Fisher, R. P., Leal, S., Milne, R., \& Bull, R. (2008).

Increasing cognitive load to facilitate lie detection: The benefit of recalling an event in reverse order. Law and Human Behavior, 32(3), 253-265.

https://doi.org/10.1007/s10979-007-9103-y

*Vrij, A., Mann, S., Leal, S., \& Fisher, R. (2010). 'Look into my eyes': Can an instruction to maintain eye contact facilitate lie detection? Psychology, Crime \& Law, 16(4), 327-348. https://doi.org/10.1080/10683160902740633

Vrij, A., Mann, S., Leal, S., \& Granhag, P. A. (2010). Getting into the minds of pairs of liars and truth tellers: An examination of their strategies. The Open Criminology Journal, 3(1).

*Vrij, A., Mann, S., Leal, S., Vernham, Z., \& Vaughan, M. (2016). Train the Trainers: A First Step towards a Science-Based Cognitive Lie Detection Training Workshop Delivered by a Practitioner: An evaluation of cognitive lie detection training. Journal of Investigative Psychology and Offender Profiling, 13(2), 110-130. https://doi.org/10.1002/jip.1443

Vrij, A., Meissner, C. A., Fisher, R. P., Kassin, S. M., Morgan, C. A., \& Kleinman, S. M. (2017). Psychological Perspectives on Interrogation. Perspectives on Psychological Science, 12(6), 927-955.

https://doi.org/10.1177/1745691617706515 
Walczyk, J. J., Igou, F. P., Dixon, A. P., \& Tcholakian, T. (2013). Advancing Lie Detection by Inducing Cognitive Load on Liars: A Review of Relevant Theories and Techniques Guided by Lessons from Polygraph-Based Approaches. Frontiers in Psychology, 4.

https://doi.org/10.3389/fpsyg.2013.00014

Walczyk, J. J., Roper, K. S., Seemann, E., \& Humphrey, A. M. (2003). Cognitive mechanisms underlying lying to questions: Response time as a cue to deception. Applied Cognitive Psychology, 17(7), 755-774.

https://doi.org/10.1002/acp.914

*Warmelink, L., Vrij, A., Mann, S., Jundi, S., \& Granhag, P. A. (2012). The effect of question expectedness and experience on lying about intentions. Acta Psychologica, 141(2), 178-183. https://doi.org/10.1016/j.actpsy.2012.07.011

Zuckerman, M., DePaulo, B. M., \& Rosenthal, R. (1981). Verbal and Nonverbal Communication of Deception. In L. Berkowitz (Ed.), Advances in Experimental Social Psychology (Vol. 14, pp. 1-59). Academic Press. https://doi.org/10.1016/S0065-2601(08)60369-X 
Table 1

The justifications of cognitive load lie detection and the corresponding research gaps

\section{Justification}

1. Liars must monitor their lies to remain plausible and consistent.

\section{Research gap(s)}

- Exponents must outline a falsifiable theory of unanticipated questions that provides enough specification to license unanticipated questioning as an unambiguous lie-detection method.

- What are the cognitive mechanisms underlying how liars and truth-tellers answer unanticipated questions - to appear plausible and consistent.

- Are there important differences between concealing information and lying?

- How do those differences make lying taxing such that one can exploit that burden to reveal lies?

- What defines a high-stakes situation when it comes to lie detection? See a suggested definition of high-stakes in the main text.

- Do liars and truth-tellers perceive high-stakes differently?

- Does the risk-taking of liars versus truth-tellers hoping for the best in highstakes situations affect interviewees' concern about their credibility in different ways?

- Does that difference yoke liars with a challenge one can capitalize on to expose lies?
2. Liars are less likely to take their credibility for granted than truth-tellers would
- Do liars and truth-tellers necessarily monitor receivers in different ways to assess whether their receiver is believing the incoming message?

- Do those differences moderate cognitive load such that interviewers can exploit the difficulty to expose lies? 
4. Liars may be engrossed in reminding themselves to play the role of a truth-teller.

5. Lying requires a mental justification truth-telling does not.

6. Liars have to suppress the truth while lying.
- How do people self-regulate in an investigative interview: do liars and truth tellers inevitably self-regulate in different ways?

- Does such self-regulation elicit different levels of cognitive load between liars and truth-tellers?

- How does that difference, if one exists, hamper the construction of lies versus truths?

- Is the moral justification of lying a significant item would-be liars contemplate after receiving an unexpected question? If so, does that contemplation necessarily make lying straining? This research gap requires a specified theory of unanticipated questions.

- Do the different reasons for wanting to be believed exert an important difference on lying versus truth-telling? For example, do the lower-level variations lead liars to want to be believed more than truth-tellers do?

- If such a difference exists, theorists must clarify how that difference imposes more cognitive load on liars versus truth-tellers. Then analysts can examine whether that presumed challenge is something interviewers can utilize to expose lies.

- Does the probing effect (e.g., Levine \& McCornack, 1996) manifest when interviewers ask unanticipated follow-up questions? This research gap requires a specified theory of unanticipated questions.

- How does suppression differ from lying? And how does that difference make lying versus truth-telling more challenging such that one can capitalize on suppression to expose lies?

- What specific behavior during lying constitutes suppression, and does that behavior change depending on the strategy chosen as the preferred method of lying.

- How do such behaviors make lying more laborious than truth-telling?

- Do liars and truth-tellers experience different levels of intrusive thoughts when communicating in investigative interviews?

- Does that difference correspond to different levels of cognitive load that one can exploit to expose lies? 
- Do mentally generating narratives to unexpected questions present a steeper challenge to

7. The mental activation of a lie is deliberate, but the truth often comes to mind automatically.

\section{liars versus truth-tellers?}

- Then stakeholders must verify whether an interviewer can capitalize on the ostensible challenge to flag lies.

- This research gap requires a specified theory of unanticipated questions. 
Table 2

Invocations and justifications of cognitive load lie detection

Invokes

Authors

Zuckerman

et al. (1981)

quote
Invokes cognitive approach premise
Cognitive load intervention
[...] systematic and measurable differences exist between honest and

1. Colwell et

al. (2009)
$\mathrm{N} / \mathrm{A}$ deceptive responding, and (2) that these differences can be elicited through interviewing that maximizes recall for honest responders while increasing the cognitive demands placed upon deceivers. (p. 202.)
Cognitive load was not necessarily manipulated. The research

examined the efficacy of

assessment criteria indicative of

deception (ACID) as a lie detection

tool. Participants (trained vs

untrained in ACID) read different

transcripts on prisoners'

description of a perpetrator in a

staged theft. After, participants

classified whether the descriptions

were truths or lies.
"According to the ACID technique, systematic differences in honest and deceptive statements can be elicited through interviewing techniques that maximize accurate recall for honest responders (i.e., that prime memory) and that place increased cognitive demand on deceptive responders (i.e., that tax cognitive resources)." (p. 70)
"These [cognitive load] techniques result in honest statements that are longer and more detailed, that add more detail throughout the interview and unfold in a less structured, more spontaneous fashion, and that include more admissions of error than deceptive statements. In other words, the use of mnemonics results in a differential recall enhancement effect: improved recall for truthful respondents in comparison to deceivers (Colwell et al., 2007 $[\ldots]) . "($ p. 70$)$

Honest respondents are attempting to recall a memory for an experienced event. [...] they are not concerned with appearing honest because they believe that their honesty is transparent [...]. [They] are able to access their memory for the original event, and they are not concerned with whether their statement contains additions, changes, or minor inconsistencies [...]. Deceptive respondents are attempting to appear confident and cooperative, and to provide a statement that is consistent while omitting or distorting any information that could lead to potential detection. [...]

\begin{abstract}
3. Colwell et $\mathrm{N} / \mathrm{A}$ for honest respondents while making deceptive responding more difficult and more apparent (Colwell et al., 2013)." (p. 228)
\end{abstract}

"These new approaches [ACID is included on that list] can contribute to a new paradigm within investigative interviewing known as Differentia 
4. Evans \& Michael

(2014)

"The cognitive complexity theory, which researchers suggest is the most promising deception theory (Vrij \& Granhag, 2012), suggests that lying is a more cognitively demanding task than truth telling for a variety of reasons. For example, only liars will need to worry whether what they say is consistent both with their previous lies and with any evidence that could be found in the future." (p. 226) deceptive respondents are accessing their lie script rather than their original memory for an experienced event, and they are quite concerned with impression management. The deceiver must inhibit her or his memory for the actual event, remember the lie script, and work to manage making impressions Colwell et al., 2013). (p. 228)

"When lying in a second language, the deceiver is simultaneously
Communicating a lie versus a truth in one's native versus non-native language. faced with the challenging task of lying. Although the relatively difficult task of speaking a second language remains for truth tellers, [...] honesty is not particularly cognitively demanding. In contrast, liars speaking a second language may not be as capable at coping with the additional cognitive demand [...]." (p. 226)

"[...] the cognitive complexity theory, focuses [...] on the differential cognitive demands faced by liars and truth-tellers [...]. This theory is based upon the idea that lying is more difficult than telling the truth (see Vrij, Fisher, Mann, \& Leal, 2006, [...]). For example, liars must suppress the truth, create a lie, monitor the interviewer's responses, remember what they have said, and ensure what they report is plausible given both currently known and discoverable information. In contrast, truth tellers simply must report their memories and may be less concerned with the investigator's responses or the plausibility of their story. Based on the theory of cognitive complexity, liars should display behaviors similar to anyone engaging in a complex cognitive task [...]." (p. 34)

"We expected that when targets were under greater cognitive load, the [lie detection] cues included in the tool [i.e., PBCAT] would be displayed more frequently/to a greater degree, especially for liars, allowing [observers] [...] to better discriminate between liars and truth-tellers." (p. 34

“[...] liars' $[s i c]$ more than truth-tellers must perform multiple tasks that rely on executive functioning resources such as working memory [...].

6. Fenn $(2015$ $\mathrm{N} / \mathrm{A}$ this typically involves reconstruction, recall of episodic memories is generally automatic." (p. 15-16)
A cognitive load interview wherein interviewees perform a concurrent secondary task. Being an ethnic minority under stereotype threat was also hypothesized to induce cognitive load.
"[...] if the working memory capacity of both liars and truthtellers is "tapped out," behavioral differences between the two are not likely to be revealed. Najdowski's (2011) model suggests that during interviewing, stigmatized ethnic minorities would experience more cognitive load than nonstigmatized ethnic groups, especially when stereotypes are primed. Consistent with these models we predict that 
"The proposed research investigates factors that moderate the effectiveness of the Cognitive Load Approach. The underlying assumption of this approach is that liars will be more cognitively challenged than truth-tellers as information processing becomes more difficult during an information-gathering interview. This should amplify behavioral differences between liars and truth-tellers." (p. 26) truth-tellers, will be under greater cognitive load when responding to

7. Fenn et al.

$(2015)$ interview questions. [...] we used a demanding cognitive load approach, the reverse order technique, to test whether imposing cognitive load wil produce qualitative differences between liars and truth tellers when interviewed about intentions." (p. 3) threatened persons (e.g., ethnic minorities under stereotype threat) will experience greater cognitive load during a cognitively demanding interview and therefore appear more deceptive than nonthreatened persons regardless of the veracity of their accounts." (p. 26)

Note. This research purposely aimed to examine whether the underlying assumption of cognitive load lie detection holds when applied to detecting true and false intentions.
"Two different cognitive load interviews were used: a low load (sequential forward order interview) and a high load (reverse order interview)". (p. 3)
"[...] understanding the differences in cognitive demand involved in recalling a past action compared to imagining a future intention would illuminate whether the underlying assumption (i.e., lying is more demanding than truth telling) of a cognitive load approach was met. If the underlying assumptions were not met (i.e., lying is not more demanding than truth telling regarding intentions) then CLAs would be less effective if used to identify intentions." (p. 2)
8. Geiselman

(2012)
$\mathrm{N} / \mathrm{A}$

$\mathrm{N} / \mathrm{A}$
Requesting for information in an unexpected manner by (a) asking interviewees to make drawings and (b) retell their story in reverse chronological order.
"Research shows that unexpected requests can trip up a liar. [(a)] The request for an illustration should be presented as a means to clarify the narrative for greater understanding [...]. Look for unusual difficulty in making the

drawing/diagram as well as for inconsistencies and a lack of additional elaboration - liars tend to have greater difficulty [...] compared with truthful subjects. [...]. [(b)] Recalling a story backward increases cognitive load, and the deceptive subject's cognitive resources already are being strained to the limit to maintain the consistency of the story." (p. 4)
9. Jordan (2016)

\section{$\mathrm{N} / \mathrm{A}$}

"The current research is based in the cognitive load method of lie detection (Vrij, Granhag, Mann, \& Leal, 2011), which posits that lying is cognitively demanding and is a primarily cognitive activity. Lying is a more cognitively effortful activity than telling the truth because lying requires suppressing truthful information, planning a lie to tell, and telling that lie in a believable way, among other cognitive tasks.
Interview styles designed to induce different amounts of cognitive load: normal order recall, reverse order recall, or dual task recall.
"[...] the main cognitive task of the truth teller is to recall the truth from long-term memory, which is a relatively automatic cognitive process. Deception however, may involve completing multiple tasks and suppressing information, all of which require mental effort [...]" (p. 13) 
10. Leal et al.

$(2010)$

$\mathrm{N} / \mathrm{A}$

$\mathrm{N} / \mathrm{A}$
The Devil's Advocate approach: An interviewing technique that first asks interviewees, liars versus truth-tellers, opinion eliciting questions. And then the

interviewer invites the interviewee to (1) defend the opinion and (2) generate arguments that oppose the opinion.

"Reasons that support an opinion are likely to be more readily

available in someone's mind than reasons that oppose an opinion." Liars may find it difficult to generate reasons that support their (false) opinion. Liars may find it difficult to restrain their (true) opinions and can more easily argue for their (true) opinion elicited by a devil's advocate question (p. 324).

"The reverse order narrative is cognitively demanding, because it requires a novel reconstruction of events. Truthtellers typically answer this request with relative ease, as they can simply access their memories and work backwards in time through associated events. [...]. By contrast, liars who rely on falsified cover stories rather than actual memories may struggle to report in reverse order because

"[...] when questions account for the liars' report strategies, they can induce inconsistency and other cues to deception (Leins et al. 2011; Vrij et al. 2009). Such questioning techniques involve imposing cognitive load upon respondents, which interviewers do by asking questions that force respondents to tell their stories in ways for which they were not prepared." (p. 320)
Interviewing mock suspects using cognitive load approach (namely, requesting reverse chronological order statements and asking unanticipated question) versus a control condition.
"[...] if liars are asked questions which they have not anticipated, they

12. Liu et al. (2010) $\mathrm{N} / \mathrm{A}$ place the liar in an awkward position with respect to what he/she has face a difficult task for several different reasons. For example, it can (a) agreed with their partners in crime to say during the interview (Vrij et al., 2009), or (b) require a retelling procedure not prepared in advance (e.g., to tell the story in backwards order, see Vrij et al., 2008)." (p. 32)
Asking interviewees unanticipated (vs. anticipated) questions they will likely lack a richly detailed memory trace from which to draw and report the information required to reconstruct their story in reverse." (p. 320)

"[unanticipated questions:] [...] respondents telling the truth [...] can access their memories of the meeting place and answer these questions with high levels of detail and consistency. By contrast, respondents lying [...] will be unable to access a critical memory and must therefore fabricate responses, typically yielding vague descriptions and inconsistencies over time (Leins et al. 2011; Vrij et al. 2009)." (p. 320). Note. Omitted information specifically illustrates an example about how liars and truth-tellers report spatial details. (p. 320)

"We selected questions which were thought to be difficult, but not impossible, to answer. [...] these questions would place the liar in a rather difficult dilemma [...]. [...] a liar's intention to actively behave in a convincing manner (e.g. try to answer difficult questions)

will overrule his/her attempts to act like a truth teller. The reason for this is that whereas it is relatively easy to imitate 
13. Logue

(2017)
Note. The cognitive load premise is not necessarily invoked to subsequently justify a cognitive lie detection technique. The premise is invoked to say lie detection cues exist.

"Vrij argues that the key to deception detection is cognitive load (Vrij, Mann, Leal, \& Fisher, 2010; Vrij, Mann, \& Leal, 2013). Lying is argued to involve a series of cognitive operations including; recalling a story that does not have rich mental associations from a script, inhibiting signs of anxiety, and monitoring the target to ensure that the false account is being accepted. Conversely, telling the truth is believed to be merely an exercise in recall." (p. 17)
Cognitive load was not necessarily manipulated as the main focus.

The research examined lie

detection by using reality

monitoring to code statements

elicited by the Cognitive Interview

for Suspects (CIS)
$\mathrm{N} / \mathrm{A}$

\section{Cognitive load was not necessarily} manipulated. The research examined the efficacy of assessment criteria indicative of deception (ACID) as a lie detection tool. Participants (trained vs untrained in ACID) read different transcripts and made veracity judgments

"The current study proposes that an alternative to arousal-based protocols to deception detection is to examine evidence of cognitive load. Although this argument has lacked a strong theoretical foundation, there are some logical assumptions that appear to support the notion. Experts
15. Patterson (2010) in the study of deception detection offer several reasons to expect that an increase in cognitive demand accompanies deception (Vrij, Fisher, Mann, Leal, Milne, \& Bull, 2007; Vrij, Fisher, Mann, \& Leal, 2006). [The seven justifications of cognitive load lie detection]." (p. 7)

"One recent, promising development in the adult literature on lie detection is the finding that interviewers can increase lie detectability by taxing the interviewee's cognitive load (e.g., Vrij et al., 2008, 2009)." (p.
Liars versus truth-tellers

performing a difficult versus easy

secondary task while undergoing an interview.

Cross-examining liars versus truthtellers in an unanticipated manner, namely asking them to first

provide statements in reverse chronological order. Then the cross-examiner asks them to repeat their statements in chronological order.
"The interviewing portion of the ACID system is referred to as the Reality Interview (RI). RI works by increasing the amount of cognitive effort required by deceivers, and assists recall for truth-tellers." Specific interviewing techniques, such as mental reinstatement of context, reverse-order recall, and the use of unanticipated questions, all serve as mnemonics to improve memory of the target event [...]. [...] These mnemonic questions increase the amount of cognitive effort required by deceivers." (p. 3)

"With increased demand, available cognitive capacity is depleted, leading to poor performance, manifested as both verbal and non-verbal indicators. This theoretical underpinning offers a new approach to deception detection. If one could employ an interview technique that depletes the available mental resources of the interviewee, overt indicators of deception may be observed in the liar (Vrij, 2008 [...])." (p. $12-13)$

"[...] [liars must] anticipate what questions the interviewer may ask so they can plan for a correct or plausible response. However, if asked an unanticipated question, liars are faced with the difficult task of attempting to reconcile their story and create a plausible

response or, feign ignorance by stating, 'I don't know' or 'I can't remember'. These responses may lead the interviewer to question the credibility of the whole statement; therefore, 
17. Sooniste et N/A

al. (2017)
"[...] lying suspects experience unanticipated questions as comparatively more

cognitively demanding to answer (for recent overviews, see Vrij \& Granhag 2012; Vrij \& Granhag 2014)." (p. 153)
Asking liars versus truth-tellers unanticipated questions, namely the planning of their stated

intentions

the lie-teller must determine, on the spot, what their best course of action may be. (p. 3)"

"[...] when answering such [unanticipated] questions, truthtellers will be able to draw on their actual memory of the planning phase. In sharp contrast, criminally inclined individuals [viz., liars] cannot rely on their memory, or any ready-made answers, when answering the same unanticipated questions." (p. 153)

"If the question is unanticipated and one person in the pair is forced to fabricate, the other individual in the pair is then forced to continue with that fabrication; hence, it requires the members of the pair to have rapid thinking and good

[...] lying includes more tasks than truth telling. Liars focus on their storytelling, but also on making a convincing impression and scrutinizing the interviewer 18. Vernham et to check whether they believe them (Buller \& Burgoon, 1996). Truth al. $(2014)$ tellers merely focus on their storytelling (Buller \& Burgoon, 1996). Consequently, liars have fewer cognitive resources left over to cope when mentally taxing interventions are implemented into the interview schedules (Vrij et al., 2008). (p. 310)
Forced turn taking between pairs of liars vs. truth-tellers when answering questions improvisation skills (Vrij, Granhag, \& Mann, 2009). If the pair lacks such skills, they will have difficulty continuing on from one another, requiring them to create more time to think before providing new information." (p. 311)

Note. The authors provide three examples, all related to improvisation, illustrating how forced turn taking enhances cognitive load; see page 311 .

"[...] cognitively demanding interviews will be particularly

"One reason why differences in non-verbal and verbal cues occur between liars and truth tellers is that lying can be more demanding than truth

19. Vrij et al. (2008) p. 25 lying contribute to this increased mental load. [The Seven justifications of cognitive load lie detection]" (p. $253-254$ )
An interviewer asking interviewees to report on a staged event in reverse chronological order. debilitating for liars, because their cognitive resources have already been partially depleted by the cognitively demanding task of lying (p. 254)." "[...] reverse order recall [...] increase $[s]$ cognitive demand because (a) it runs counter to the natural forward-order coding of sequentially occurring events [...] and (b) it disrupts reconstructing events from a schema [...]." (p. 255)
20. Vrij et al. p. $328 \&$ p. (2010)
"We assume that, generally, lying is more cognitively demanding than truth telling." (p. 327). "[The seven justifications of cognitive load lie detection (p. 328 - 329)]."
Note. The authors invoke the seven justifications of cognitive load lie detection but not to explain the cognitive load manipulation necessarily. (p. 328 - 329)

Communicating a lie versus a truth while maintaining eye contact with "When they need to concentrate on what to say, people the interviewer to switch off from environmental stimulation either by closing their eyes or focusing on an information-poor aspect of the environment, such as a ceiling, wall, floor, etc. By asking people to maintain eye contact, this commonly used and often unconscious strategy to reduce cognitive 

interviewee is likely to experience cognitive load." (p. 330)

Imposing cognitive load: "[...] If cognitive demand is further raised, which could be achieved by making additional requests, liars may be less able than truth tellers to cope with these additional requests (Vrij, Granhag, Mann, \& Leal, 2011)" (p. 110)

Encouraging interviewees to say more: "[...] help[s] truth tellers if they provide much information, because the richer an account is perceived to be in detail, the more

Interviewers received training to use the three approaches of

"The core of the cognitive lie detection approach is that investigators can magnify the differences in cognitive cues displayed by truth tellers and liars through interventions based on cognitive principles that make the liars' task more cognitively demanding." (p. 110) (a) the dection when

interviewing mock suspects. Th approaches were imposing cognitive load, encouraging interviewees to say more, and asking unanticipated questions. likely it is to be believed [...]. Moreover, the additional information truth tellers provide could give leads to investigators to check. Liars may find it cognitively too difficult to add as many details as truth tellers do.

Alternatively, if liars do add substantial detail, the additional information may sound less plausible. In addition, liars may be reluctant to add more information out of fear that it will provide leads to investigators and consequently, give their lies away." (p. 111)

Unanticipated questions: [...] Though liars can refuse to answer unexpected questions by saying "I don't know" or "I can't remember", such responses will create suspicion if they are about central aspects of the target event. A liar, therefore, has little option other than to fabricate a plausible answer on the spot, which is cognitively demanding. (p. 111)
22. Vrij et al.

(2016)

\section{$\mathrm{N} / \mathrm{A}$}

Ditto (p. 111)
Ditto

Ditto (p. $111-112)$
"When asked about their past activities we expected liars to give less detailed answers than truth tellers, because fabricating answers to such questions may be more difficult than truth telling. In addition, liars may 23. Vrij, Lea et al. $\mathrm{N} / \mathrm{A}$ avoid providing detailed information because they run the risk of lie detectors checking the veracity of the details they provide, or of contradicting themselves. The more liar [sic] say, the more opportunity they give to lie detectors to check the veracity of the statement, and the more chance there is of contradicting themselves." (p. 212)

Cognitive load was not necessarily manipulated. Participants were

interviewed about their intentions and past activities.

Note. The authors describe inquiries about intentions as unanticipated questions (p. 217) 
"The present experiment [...] uses the cognitive load approach (Vrij,

Fisher, Mann, \& Leal, 2006, [...]). The core of this approach is that lying is more cognitively demanding than telling the truth. Several factors contribute to this increased mental load. Liars have to fabricate a story,

24. Warmelink

et al.

$(2012)$

remember what really happened and remember what they said earlier in

the interview to avoid contradicting themselves. In addition, liars pay more attention to their own credibility, which truth tellers tend to take more for granted (DePaulo et al., 2003; [...]). Therefore, in an effort to heighten their credibility, liars monitor themselves more than truth

tellers for possible cues to deceit whilst monitoring the interviewer more

looking for signs of whether or not they are being believed." (p. 178)
Answering unexpected versus expected questions about a

forthcoming trip: unexpected

questions comprised of inquiries

about the most important event of

the trip, the method of travel to

the destination, and how the trip

was planned. Expected questions

included factual questions about

the core events of the trip.
"[...] because liars cannot have prepared answers to such [unexpected] questions. They are therefore likely to give fewer details than truth tellers when answering such questions. In sum, this would mean that liars would give more detail than truth tellers when answering the expected questions, but would give fewer details than truth tellers when answering the unexpected questions." (p. 179)

\section{Zimmerma}


A Complete Illustration of the Thematic Analysis

The highlighted segments depict the texts used as a basis of themes defined in the analysis. The different colors of the highlighted text indicate the corresponding theme of justification.

Liars must monitor their lies to remain plausible and consistent (J1); Liars are less likely to take their credibility for granted (J2); L nay be engrossed in playing the role of a truth teller (J4); Lying requires a mental justification truth-telling does not (J5);

Lying requires a mental justification truth-telling does not (J5); Liars have to suppress the truth while lying;

\begin{tabular}{|c|c|c|}
\hline \multirow{3}{*}{ Authors } & Invokes & Invokes cognitive approach premis \\
& Zuckerman & Implicit invocation = yellow highlight \\
& et al. (1981) & Euote
\end{tabular}

[... systematic and measurable differences exist between honest and

1. Colwell et N/A deceptive responding, and (2) that these differences can be elicited through

al. (2009) $\mathrm{N} / \mathrm{A}$

\begin{tabular}{|l|l|} 
& \\
\hline & \\
\hline &
\end{tabular}

2. Colwell et

al. (2012)

$\mathrm{N} / \mathrm{A}$

interviewing that maximizes recall for honest responders while increasing the

cognitive demands placed upon deceivers. (p. 202.)

"According to the ACID technique, systematic differences in honest and deceptive statements can be elicited through interviewing techniques that maximize accurate recall for honest responders (i.e., that prime memory) and that place increased cognitive demand on deceptive responders (i.e., that tax cognitive resources)." (p. 70)

"These new approaches [ACID is included on that list] can contribute to a new paradigm within investigative interviewing known as Differential Recall

3. Colwell et al. (2015)
$\mathrm{N} / \mathrm{A}$
Enhancement-DRE - the use of techniques that increase recall for honest

respondents while making deceptive responding more difficult and more

Ditto
Cognitive load intervention

Cognitive load was not necessarily manipulated. The research examined the efficacy of assessment criteria indicative of deception (ACID) as a lie detection tool. Participants (trained vs untrained in ACID) read different transcripts on prisoners' description of a perpetrator in a staged theft. After, participants classified whether the descriptions were truths or lies.

\section{Ditto}

Cose [cognitive load] techniques result in honest stater that are longer and more detailed, that add more detail throughout the interview and unfold in a less structured spontaneous fashion, and that include more admissions c error than deceptive statements. In other words, the use mnemonics results in a differential recall enhancement ef

(Colwell et al., 2007 [...]).” (p. 70)

experienced event. [...] they are not concerned with appe honest because they believe that their honesty is transpa [...]. [They] are able to access their memory for the origin event, and they are not concerned with whether their statement contains additions, changes, or minor inconsistencies [...]. 


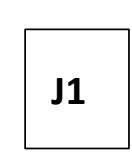

4. Evans \& Michael

(2014)

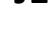

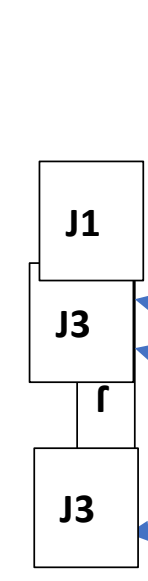

J6

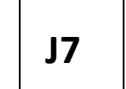

57

(2013)
6. Fenn (2015)
"The cognitive complexity theory, which researchers suggest is the most promising deception theory (Vrij \& Granhag, 2012), suggests that lying is a For example, only liars will need to worry whether what they say is For example,

" (p. 226)

"[...] the cognitive complexity theory, focuses [...] on the differential cognitive demands faced by liars and truth-tellers [...]. This theory is based upon the idea that lying is more difficult than telling the truth (see Vrij, Fisher, Mann, \& Leal, 2006, [...]). For example, liars must suppress the truth, create a lie, monitor the interviewer's responses, remember what they have said, and ensure what they

5. Evans et al.
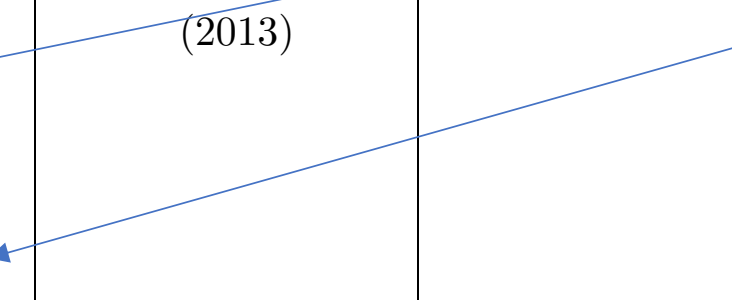
task [...]." (p. 34)

"We expected that when targets were under greater cognitive load, the [lie detection] cues included in the tool [i.e., PBCAT] would be displayed more frequently/to a greater degree, especially for liars, allowing [observers] [...] to better discriminate between liars and truth-tellers." (p. 34)

"[...] liars' $[s i c]$ more than truth-tellers must perform multiple tasks that rely on executive functioning resources such as working memory [...].

Although this typically

involves reconstruction, recall of episodic memories is generally automatic." (p. 15- 16)

"The proposed research investigates factors that moderate the effectiveness of the Cognitive Load Approach. The underlying assumption of this approach is that liars will be more cognitively challenged than truth-tellers
Communicating a lie versus a truth in one's native versus non-native language.

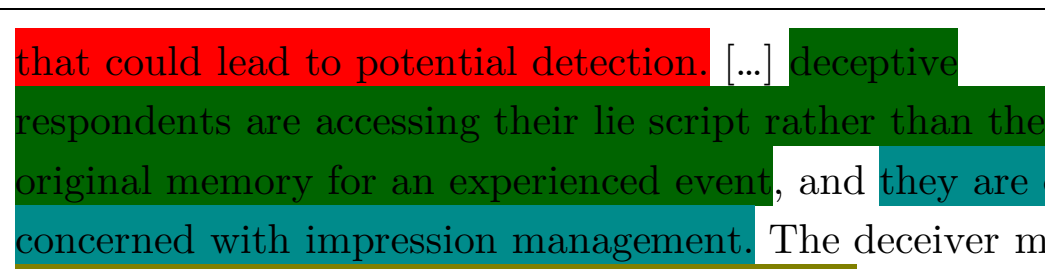
inhibit her or his memory for the actual event, remembe lie script, and work to manage making impressions Colw al., 2013). (p. 228)

"When lying in a second language, the deceiver is simultaneously

faced with the challenging task of lying.
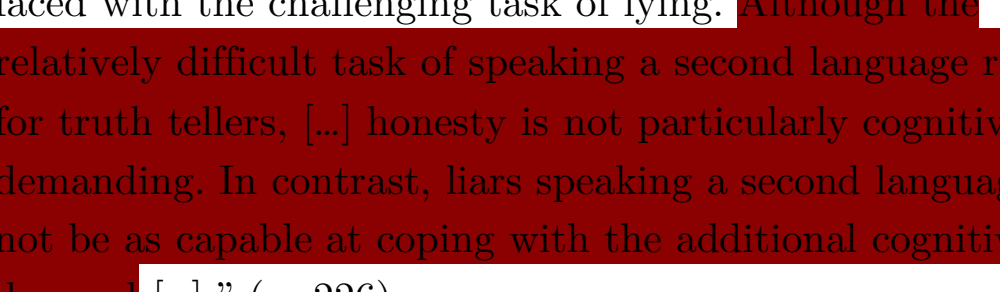

[...]." (p. 226)
A cognitive load interview wherein interviewees perform a concurrent secondary task. Being an ethnic minority under stereotype threat was also hypothesized to induce cognitive load.
"[...] if the working memory capacity of both liars and tr tellers is "tapped out," behavioral differences between th are not likely to be revealed. Najdowski's (2011) model suggests that during interviewing, 


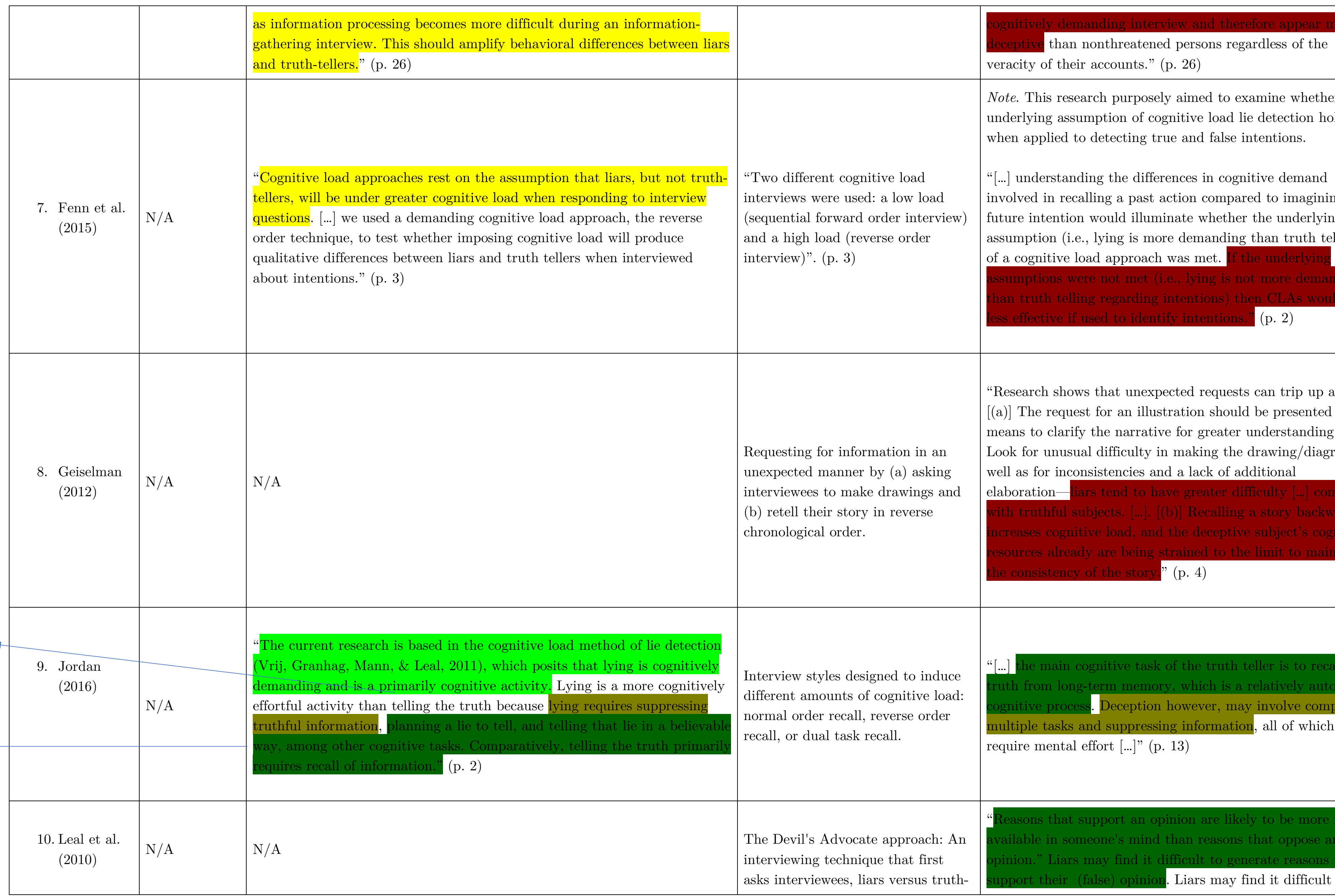




\begin{tabular}{|c|c|c|c|c|}
\hline & & & $\begin{array}{l}\text { tellers, opinion eliciting questions. } \\
\text { And then the interviewer invites the } \\
\text { interviewee to (1) defend the opinion } \\
\text { and (2) generate arguments that } \\
\text { oppose the opinion. }\end{array}$ & $\begin{array}{l}\text { restrain their (true) opinions and can more easily argue } \\
\text { their (true) opinion elicited by a devil's advocate questio } \\
\text { 324). }\end{array}$ \\
\hline $\begin{array}{l}\text { 11. Leins et al. } \\
\text { (2017) }\end{array}$ & $\mathrm{N} / \mathrm{A}$ & $\begin{array}{l}\text { "[...] when questions account for the liars' report strategies, they can induce } \\
\text { inconsistency and other cues to deception (Leins et al. 2011; Vrij et al. } \\
\text { 2009). Such questioning techniques involve imposing cognitive load upon } \\
\text { respondents, which interviewers do by asking questions that force } \\
\text { respondents to tell their stories in ways for which they were not prepared." } \\
\text { (p. 320) }\end{array}$ & $\begin{array}{l}\text { Interviewing mock suspects using a } \\
\text { cognitive load approach (namely, } \\
\text { requesting reverse chronological } \\
\text { order statements and asking } \\
\text { unanticipated question) versus a } \\
\text { control condition. }\end{array}$ & $\begin{array}{l}\text { "The reverse order narrative is cognitively demandil } \\
\text { because it requires a novel reconstruction of events. Tru } \\
\text { ellers typically answer this request with relative ease, as } \\
\text { can simply access their memories and work backwards in } \\
\text { through associated events. [...]. By contrast, liars who re } \\
\text { falsified cover stories rather than actual memories may } \\
\text { struggle to report in reverse order because they will likei } \\
\text { a richly detailed memory trace from which to draw and } \\
\text { the information required to reconstruct their story in rer } \\
\text { (p. 320) } \\
\text { "[unanticipated questions:] [...] respondents telling th. } \\
\text { truth [...] can access their memories of the meeting place } \\
\text { answer these questions with high levels of detail and } \\
\text { consistency. By contrast, respondents lying [...] will be u } \\
\text { to access a critical memory and must therefore fabricate } \\
\text { responses, typically yielding vague descriptions and } \\
\text { inconsistencies over time (Leins et al. 2011; Vrij et al. } 20 \\
\text { (p. 320). Note. Omitted information specifically illustrat } \\
\text { example about how liars and truth-tellers report spatial } \\
\text { details. (p. 320) }\end{array}$ \\
\hline $\begin{array}{l}\text { 12. Liu et al. } \\
\text { (2010) }\end{array}$ & $\mathrm{N} / \mathrm{A}$ & $\begin{array}{l}\text { "[...] if liars are asked questions which they have not anticipated, they face a } \\
\text { difficult task for several different reasons. For example, it can (a) place the } \\
\text { liar in an awkward position with respect to what he/she has agreed with } \\
\text { their partners in crime to say during the interview (Vrij et al., 2009), or (b) } \\
\text { require a retelling procedure not prepared in advance (e.g., to tell the story } \\
\text { in backwards order, see Vrij et al., 2008)." (p. 32) }\end{array}$ & $\begin{array}{l}\text { Asking interviewees unanticipated } \\
\text { (vs. anticipated) questions }\end{array}$ & $\begin{array}{l}\text { "We selected questions which were thought to be difficu } \\
\text { not impossible, to answer. [...] these questions would plar } \\
\text { liar in a rather difficult dilemma [...]. [...] a liar's intentio } \\
\text { actively behave in a convincing manner (e.g., try to ans } \\
\text { difficult questions) } \\
\text { will overrule his/her attempts to act like a truth teller. } \\
\text { reason for this is that whereas it is relatively easy to im } \\
\text { truth tellers when having prepared what to say, it is a n } \\
\text { more difficult task to do this on the spot." (p. } 32 \text { ) }\end{array}$ \\
\hline $\begin{array}{r}\text { 13. Logue } \\
(2017)\end{array}$ & p. 8 & $\begin{array}{l}\text { Note. The cognitive load premise is not necessarily invoked to subsequently } \\
\text { justify a cognitive lie detection technique. The premise is invoked to say lie } \\
\text { detection cues exist. } \\
\text { "Vrij argues that the key to deception detection is cognitive load (Vrij, } \\
\text { Mann, Leal, \& Fisher, 2010; Vrij, Mann, \& Leal, 2013). Lying is argued to }\end{array}$ & $\begin{array}{l}\text { Cognitive load was not necessarily } \\
\text { manipulated as the main focus. The } \\
\text { research examined lie detection by } \\
\text { using reality monitoring to code } \\
\text { statements elicited by the Cognitive } \\
\text { Interview for Suspects (CIS). }\end{array}$ & $\mathrm{N} / \mathrm{A}$ \\
\hline
\end{tabular}




\begin{tabular}{|c|c|c|c|c|c|}
\hline & & & $\begin{array}{l}\text { involve a series of cognitive operations including; recalling a story that does } \\
\text { not have rich mental associations from a script, inhibiting signs of anxiety, } \\
\text { and monitoring the target to ensure that the false account is being accepted } \\
\text { Conversely, telling the truth is believed to be merely an exercise in recall." } \\
\text { (p. 17) }\end{array}$ & & \\
\hline & $\begin{array}{l}\text { 14. Montalvo } \\
\text { et al. } \\
\text { (2013) }\end{array}$ & $\mathrm{N} / \mathrm{A}$ & $\mathrm{N} / \mathrm{A}$ & $\begin{array}{l}\text { Cognitive load was not necessarily } \\
\text { manipulated. The research examined } \\
\text { the efficacy of assessment criteria } \\
\text { indicative of deception (ACID) as a } \\
\text { lie detection tool. Participants } \\
\text { (trained vs untrained in ACID) read } \\
\text { different transcripts and made } \\
\text { veracity judgments }\end{array}$ & $\begin{array}{l}\text { "The interviewing portion of the ACID system is referre } \\
\text { the Reality Interview (RI). RI works by increasing the a } \\
\text { of cognitive effort required by deceivers, and assists reca } \\
\text { truth-tellers." Specific interviewing techniques, such as } \\
\text { reinstatement of context, reverse-order recall, and the u} \\
\text { unanticipated questions, all serve as mnemonics to impr } \\
\text { memory of the target event [...]. [...] These mnemonic qu } \\
\text { increase the amount of cognitive effort required by dece } \\
\text { (p. 3) }\end{array}$ \\
\hline J1 - J7 & $\begin{array}{l}\text { 15. Patterson } \\
\text { (2010) }\end{array}$ & p. 8 & $\begin{array}{l}\text { "The current study proposes that an alternative to arousal-based protocols } \\
\text { to deception detection is to examine evidence of cognitive load. Although } \\
\text { this argument has lacked a strong theoretical foundation, there are some } \\
\text { logical assumptions that appear to support the notion. Experts in the study } \\
\text { of deception detection offer several reasons to expect that an increase in } \\
\text { cognitive demand accompanies deception (Vrij, Fisher, Mann, Leal, Milne, }\end{array}$ & $\begin{array}{l}\text { Liars versus truth-tellers performing } \\
\text { a difficult versus easy secondary task } \\
\text { while undergoing an interview. }\end{array}$ & $\begin{array}{l}\text { "With increased demand, available cognitive capacity is } \\
\text { depleted, leading to poor performance, manifested as bo } \\
\text { verbal and non-verbal indicators. This theoretical } \\
\text { underpinning offers a new approach to deception detecti } \\
\text { one could employ an interview technique that depletes t } \\
\text { available mental resources of the interviewee, overt indi }\end{array}$ \\
\hline & & & $\begin{array}{l}\text { \& Bull, 2007; Vrij, Fisher, Mann, \& Leal, 2006). [The seven justifications of } \\
\text { cognitive load lie detection]." (p. 7) }\end{array}$ & & $\begin{array}{l}\text { of deception may be observed in the liar (Vrij, } 2008[. . .]) \\
12 \text { - 13) }\end{array}$ \\
\hline NJ & $\begin{array}{c}\text { 16. Saykaly et } \\
\text { al. (2016) }\end{array}$ & p. 3 & $\begin{array}{l}\text { "One recent, promising development in the adult literature on lie detection } \\
\text { is the finding that interviewers can increase lie detectability by taxing the } \\
\text { interviewee's cognitive load (e.g., Vrij et al., 2008, 2009)." (p. 3) }\end{array}$ & $\begin{array}{l}\text { Cross-examining liars versus truth- } \\
\text { tellers in an unanticipated manner, } \\
\text { namely asking them to first provide } \\
\text { statements in reverse chronological } \\
\text { order. Then the cross-examiner asks } \\
\text { them to repeat their statements in } \\
\text { chronological order. }\end{array}$ & $\begin{array}{l}\text { "[...] [liars must] anticipate what questions the interview } \\
\text { ask so they can plan for a correct or plausible response. } \\
\text { However, if asked an unanticipated question, liars are fe } \\
\text { with the difficult task of attempting to reconcile their s } \\
\text { and create a plausible } \\
\text { response or, feign ignorance by stating, 'I don't know' } \\
\text { can't remember'. These responses may lead the intervie } \\
\text { question the credibility of the whole statement; therefor } \\
\text { lie-teller must determine, on the spot, what their best c } \\
\text { of action may be. (p. 3)" }\end{array}$ \\
\hline NJ & $\begin{array}{l}\text { 17. Sooniste et } \\
\text { al. (2017) }\end{array}$ & $\mathrm{N} / \mathrm{A}$ & $\begin{array}{l}\text { "[...] lying suspects experience unanticipated questions as comparatively } \\
\text { more } \\
\text { cognitively demanding to answer (for recent overviews, see Vrij \& Granhag } \\
\text { 2012; Vrij \& Granhag 2014)." (p. 153) }\end{array}$ & $\begin{array}{l}\text { Asking liars versus truth-tellers } \\
\text { unanticipated questions, namely the } \\
\text { planning of their stated intentions }\end{array}$ & $\begin{array}{l}\text { "[...] when answering such [unanticipated] questions, } \\
\text { truthtellers will be able to draw on their actual memory } \\
\text { planning phase. In sharp contrast, criminally inclined } \\
\text { individuals [viz., liars] cannot rely on their memory, or } \\
\text { ready-made answers, when answering the same unantici } \\
\text { questions." (p. 153) }\end{array}$ \\
\hline
\end{tabular}




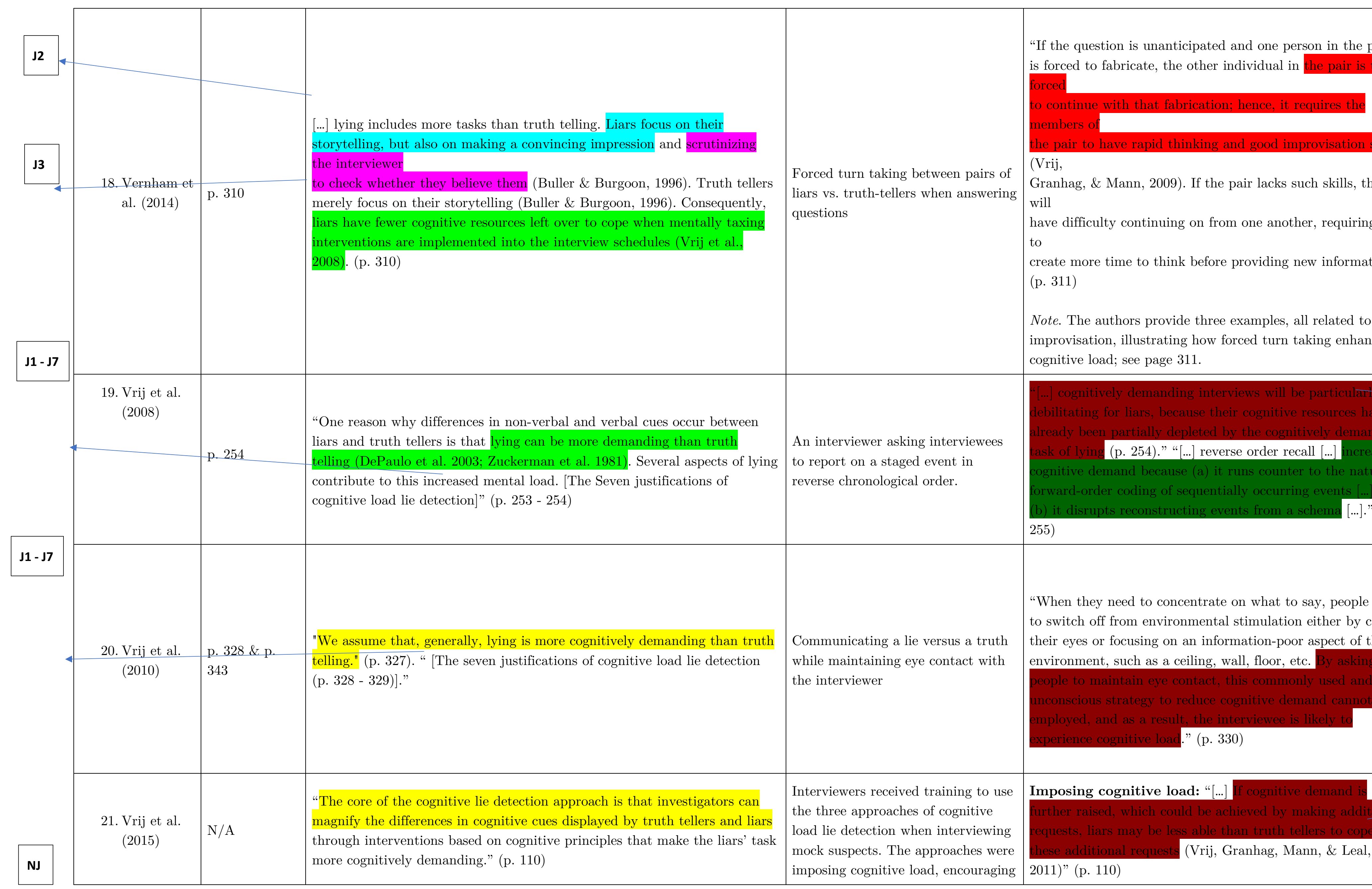




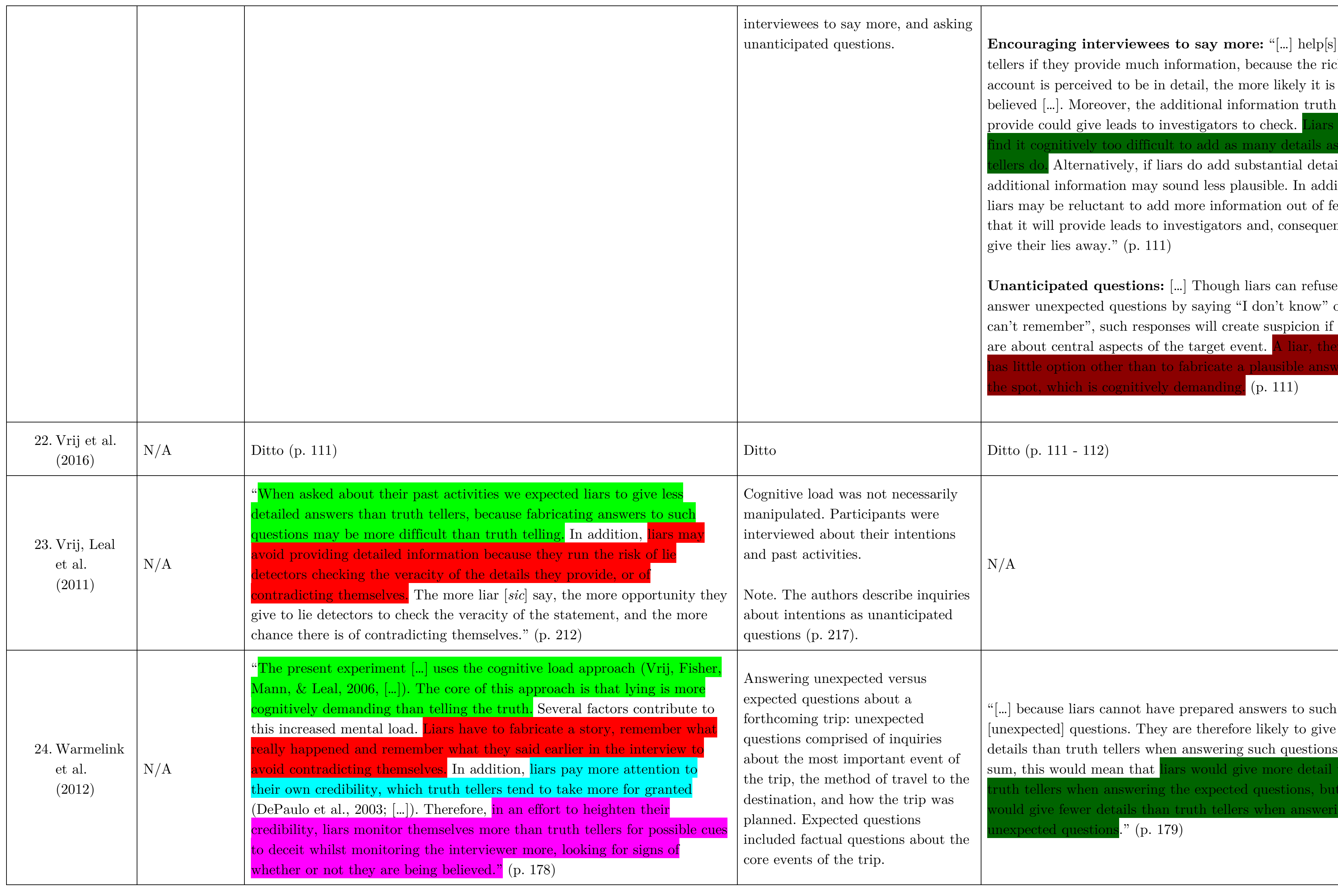




\section{Appendices}

\section{Appendix 1: An alternative interpretation of the cognitive load lie detection}

\section{premise}

One could interpret the cognitive load premise in another way besides the counterfactual premise ${ }^{4}$. Cognitive load techniques further raise a preexisting mental demand of lying versus truth-telling - call this the preexisting-demand premise.

The proposal that one can further raise, enhance, or magnify the cognitive demand of lying versus truth-telling invokes the preexisting-demand premise by supposing that a would-be liar has a problem one can aggravate. That invocation, taken at face value, assumes a would-be liar contends a difficulty before lying. A difficulty must necessarily exist before one can further raise it - otherwise, there is nothing to aggravate. The preexisting-demand premise belies a problematic inference: that lying is burdensome before one enacts the behavior. This proposition is not feasible. The effort a behavior requires can arguably only manifest during its performance, not before. Thus, one cannot further raise, enhance, or magnify the supposed initial difficulty of lying versus truthtelling. The presumed difficulty - to be enhanced - does not exist. The mental demand of lying is likely to appear only when the would-be receiver poses a difficult question. More

\footnotetext{
${ }^{4}$ The counterfactual premise is that cognitive load techniques further raise the mental strain a liar would have experienced had a cognitive load technique not been used, but after being asked a question — call this the counterfactual premise.
} 
difficult questions likely introduce a heavier cognitive load than less difficult questions ostensibly would. Before the inquiry, the would-be sender has no challenge to grapple with.

A critic may object by arguing that the issues I have flagged with the preexistingdemand premise concern wording, not necessarily a conceptual problem; I concede. However, because that premise can come up, I discuss it for a pragmatic reason. By showing the attendant flaws, I hope to preempt possible future objections that invoke the preexisting-demand premise. Let us now abandon the preexisting-demand premise.

\section{Appendix 2: Empirical evidence and the basis to critique the justifications}

I attempted to publish this review in the journal where the, arguably, seminal article espousing cognitive load lie detection resides (i.e., Vrij \& Granhag, 2012). The editorial process raised some metascientific objections I did not realize would be items to contend with ${ }^{5}$. Delving into those issues is an opportune springboard to prevent such limited objections from surfacing in the future, allowing the field to focus on the prudent way forward.

\footnotetext{
${ }^{5}$ In the previous version of this article, I assumed the notion of falsification would be evident. This version makes the argument more explicit. I can provide the editorial correspondence to auditors who want to ascertain whether the objections noted here were truly raised in a previous review. All versions of this article are accessible here: https://psyarxiv.com/6zs5j/ (Version 1)
} 
The objectors argued that suppose the review rejects the general premise that lying demands more cognitive resources than truth-telling: the review must provide empirical evidence to support the rejection. Let us address this objection. The present review raised limitations with the cognitive load lie detection premise: imposing cognitive load can expose lies. Whether lying demands more cognitive resources than truth-telling is a part of the cognitive load premise: one must consider the entire premise. The seven justifications of the cognitive load lie detection premise, in their current form, are severely underspecified; analysts can hardly falsify the justifications and, by extension, the central premise. This review highlights the need to bring the cognitive load lie detection premise to a place where analysts can attempt to falsify it by examining the fitness of the seven justifications. Thus, one cannot provide empirical evidence to reject a part, or the full cognitive load lie detection premise, at least not with the current state of the literature.

In the introduction, I discussed the most recent meta-analyses indicating that the field must scrutinize the cognitive load lie detection premise (viz, Mac Giolla \& Luke, 2021; Verschuere et al., 2018). Another objection claimed that those meta-analyses demonstrate boundary conditions of a cognitive approach to lie detection, not that we must reject such an approach. Note that the present review does not claim we should reject cognitive load lie detection outright. The objector offered these reasons: Verschuere et al. (2018) write that "our findings support the cognitive theory of lying (p. 467)"; Mac 
Giolla and Luke (2021) write that "we remain optimistic about future research on the topic (p. 387)."

I have already clarified that the issue at stake is the validity of the cognitive load lie detection premise, not a cognitive theory of lying. Other cognition-based lie detection frameworks exist, for example, the strategic use of evidence (SUE) framework, which advocates the use of available evidence to reveal inconsistencies in what liars say (Granhag \& Hartwig, 2015). SUE does not necessarily assume that imposing cognitive load can expose lies. What about the promising future the meta-analyses allegedly mention?

Verschuere et al. (2018) note that by a cognitive theory of lying, they mean the idea that lying can be more challenging than telling the truth, assuming slower reaction times (RT) suggest one was contending cognitive load (p. 467). However, Verschuere et al. (2018) note that their findings, based on RT, do not support the specific cognitive load lie detection premise ${ }^{6}$ : "imposing additional load may in fact hinder truth-telling, to the extent that the differences between lying and truth-telling become less apparent (p. 467)". As I noted in the introduction, Mac Giolla and Luke's (2021) positive spin on their results should not prevent scrutiny. The authors qualified the presumed improvements cognitive load lie detection brings. That result is plagued by "publication bias, considerable heterogeneity between studies, and a lack of research on important practical issues, such

\footnotetext{
${ }^{6}$ See also the footnote by Verschuere et al. (2018, p. 463).
} 
as the influence of counter-measures (p. 390)". In all, the meta-analyses (viz, Mac Giolla \& Luke, 2021; Verschuere et al., 2018) support the thesis of the present review: psychology researchers must reexamine the foundation of the cognitive load lie detection premise.

The objectors raised another species of issues. If the present review says the justifications for the (presumed) different cognitive demands between lying and truthtelling are weak, what are the better explanations as validated by empirical evidence? Additionally, if the present review takes issue with the techniques or measures the cognitive load (lie detection) premise proposes, what has been done wrong and what could have been done instead?

This review argues that the justifications of the cognitive load lie detection premise are weak; that lying demands more cognitive resources than truth-telling is a part of that premise. The issue at stake is whether one can exploit the ostensible challenge by imposing cognitive load to expose lies. The meta-analyses just described indicate that researchers must be cautious about the cognitive load lie detection premise. The burden of proof to provide better and empirically validated justifications rests on the proponents of the premise. Asking an analyst to provide better explanations supporting the cognitive load lie detection premise would mean that the analysts should take the premise for granted. Ignoring a theoretically ambiguous premise is the very issue this article argues against. 